\title{
Preventing Falls in an Acute Care Setting Through Patient and Family Education
}

\author{
Donna Swink Hahn \\ Staunton, Virginia \\ BSN, Eastern Mennonite University, 1978 \\ MSN, University of Virginia, 1988
}

\begin{abstract}
A Capstone Presented to the Graduate Faculty of the University of Virginia in Candidacy for the Degree of Doctor of Nursing Practice
\end{abstract}

\author{
School of Nursing \\ University of Virginia \\ December, 2013
}

Kathleen Cox, PhD, RN

Lois Kercher, PhD, RN

Signature of Chair

Signature of Member

Kathleen Fletcher, DNP, RN, GNP-BC, FAAN

Signature of Member

"On my honor as a student, I have neither given nor received unauthorized aid on this assignment" 


\begin{abstract}
Patient falls are of particular interest to hospitals as they are the leading cause of adverse events in this setting and the Center for Medicare and Medicaid no longer reimburses hospitals for care related to serious injury from a patient fall. Evidence based protocols and the literature support multifaceted fall prevention interventions, one of which is falls prevention education to patients and their families. A gap was found in the availability of evidence based falls prevention education.

The study sought to determine if falls and falls with injury rates are decreased in older adults when patients and family support are provided an educational video on falls prevention based on the theory of planned behavior and social support theory. A 36 bed medical unit in a 238 bed community hospital provided a sample of convenience for this quasi-experimental two group design study with a comparison group $(N=100)$ receiving usual care and education brochure and intervention group $(N=92)$ receiving usual care, education brochure, and video with teach-back.

The study was unable to reinforce social support due to the small numbers of family viewing the video $(N=7)$. No statistical difference between groups was found based on rates of falls per 1000 patient days, $\chi 2(1, N=192)=1.86, p=.270$ due to the small number of falls. However, a statistically significant difference was demonstrated between groups in the proportion of patients receiving any falls education intervention based on the study phase, $\chi 2(1, N=192)=0.20, p<.001$ and exceeded Cohen's $(1992)$ convention for medium effect size. This statistical difference between groups for fidelity of education intervention supports clinically significant findings when comparing the frequency of fall rates between groups (Phase $1=6.01$ vs. Phase $2=0.0$ ). Interestingly,
\end{abstract}


$70 \%$ of intervention participants viewed a falls education video and $94 \%$ of these participants received follow up by way of teach-back by the Registered Nurse. The results of this study provide clinically significant support for previous study's findings for the use of multimedia education and teach-back.

Keywords: falls, education, hospital, acute care, older, education, and planned behavior. 
Table of Contents

Section I: Introduction and Purpose..........................................5

Section II: Review of the Literature..................................................12

Section III: Method..........................................................25

Section IV: Results...........................................................35

Appendix A: Figure 1: Conceptual framework for an educational intervention for influencing intent to follow the falls protocol based on the theories of planned behavior and social support.................................................48-50

Appendix B: Description of Literature......................................51-68

Appendix C: Social Marketing Process.......................................69-70

Appendix D: Content Outline for Educational Video ..........................71-75

Appendix E: Content of Falls Educational Brochure...........................76-77

Appendix F: Post Fall Huddle Report........................................78-79

Appendix G: Informed Consent Intervention Group..........................80-84

Appendix H: Informed Consent Comparison Group...........................85-89

Appendix I: Institutional Review Board Approvals............................90-94

Appendix J: Journal Guidelines...........................................95-102

Appendix K: Table 1: Demographic and Length of Stay Characteristics.....103-104

References........................................................................105

Appendix L: Draft Manuscript....................................................113 


\section{Section I: Introduction and Purpose}

\section{Introduction}

Falling is a serious public health problem which can reduce quality of life and cause death. According to a report from the Center for Disease Control and Prevention (CDCP) falls in older adults, 65 years of age and older, are the leading cause of injury death and the most common cause of hospital admissions for trauma (CDCP, 2005). Further, traumatic brain injury accounted for $46 \%$ of fall injury deaths in 2000 and predicts that without intervention, there will be 500,000 hip fractures per year related to falls by 2040. In addition, hip fractures may cause significant functional impairment, require nursing home placement, and one in five hip fractures result in death (CDCP, 2005).

The United States Department of Health and Human Services has promoted interest in falls prevention in the Healthy People campaigns. "Healthy People 2010" and “Healthy People 2020" include objectives to address the public health issue of falls. "Healthy People 2010" sought to prevent unintentional injuries with objectives to reduce deaths from falls and prevent hip fractures (U. S. Department, 2000). "Healthy People 2020 " includes objectives to prevent an increase in falls related deaths in persons of all ages and adults age 65 and older (U.S. Department, 2010). In addition, reducing emergency department visits related to falls is also an objective for older adults (U.S. Department, 2010).

Falls are reported to be the most frequently occurring adverse event for adult patients in hospitals (Currie, 2008). While patients of all ages fall when hospitalized, 
several researchers have found a correlation between falls and increased age (Currie, 2008; Hitcho et al., 2004; Krauss et al., 2007). Between $26 \%$ and $42 \%$ of hospital falls result in patient injury and between $2.4 \%$ and $8 \%$ of hospital falls result in serious injury (Krauss et al., 2007; Hitcho et al., 2004).

In 2008 the Center for Medicare and Medicaid Services (CMS) determined that falls with trauma were an identified hospital acquired condition, defined as easily prevented when evidenced based guidelines are used (CMS, 2011). Treatments related to hospital acquired conditions, and therefore injuries due to falls in acute care, are no longer reimbursed by CMS. The costs to hospitals can be significant as researchers have shown increased lengths of hospital stay after a fall to cause an additional 6.3 to 12 days, and an increased mean cost up to $\$ 13,316$ as a result of serious falls (Bates, Pruess, Souney, \& Platt, 1995; Wong et al., 2011).

Falls in the hospital setting are of concern to nursing and are endorsed by the National Quality Forum as a nurse sensitive indicator for acute care hospitals (National Quality Forum, 2009). The Magnet Nursing Designation awarded by the American Nurse Credentialing Center (2012) has become a coveted credential by many healthcare organizations around the world and is considered an indication of high quality nursing practice. Standards of Magnet require that hospital personnel monitor certain nurse sensitive outcome indicators and compare the hospital's performance for these outcomes to national benchmarks; the expectation is that Magnet hospitals sustain results to outperform the mean (ANCC, 2008). Therefore interventions to prevent patient falls are needed. 
An evidence based falls prevention protocol is available from the Agency for Health Care Quality. This protocol was developed by members of the Institute for Clinical Systems Improvement (ICSI), a non-profit organization of sixty two medical groups sponsored by five Minnesota and Wisconsin health plans. The protocol is titled "Prevention of falls (acute care). Health care protocol" (ICSI, 2010; Degelau, et.al, 2012). The protocol includes providing education to patient and family on fall prevention but does not provide evidence for the most effective education content or delivery method for the intervention. The Joint Commission (2011) and the Agency for Healthcare Research and Quality (2011) have both launched campaigns to encourage patients to speak up for their own safety and to have family or a significant other present when managing health care issues. However no specific direction for the family member's role in fall prevention is provided.

A gap exists in the availability of evidence based messages and content for acute care education on fall prevention for patients and their families. Existing videos and brochures related to fall prevention are primarily targeted to the older adult in the community and do not include messages for family and significant others (TJC, 2011; U. S. Department, 2000; U. S. Department, 2010). Although one falls prevention video for purchase was found online, it did not include specific messages related to the family's role in the prevention of patient falls (Envision, 2012).

Evidence based protocols and the literature support multifaceted fall prevention interventions, one of which is falls prevention education to patients and their families (ICSI, 2010; Hill et al., 2009; Haines et al., 2011; Dykes et al., 2009). There is some 
evidence that a multimedia educational delivery method with one to one follow up by a health counselor improves knowledge and outcomes for the older adult (Haines, et al., 2011; Hill et al., 2009). The purpose of this study was to develop an evidence based education video on falls prevention for the hospitalized older patient, to include this education to a family member or support person, perform teach-back with the patient, and to compare the difference in fall rates between patients and families in an intervention group who received a fall prevention brochure and viewed an investigator developed video and patients in a comparison group who only received a falls prevention brochure.

\section{Theoretical Framework}

Individual health behavior theories can provide a structure for designing a program to promote health and prevent health problems (Edberg, 2007). Only two studies were found comparing educational methods for the hospitalized patient, both designed on the health belief model; however neither study discussed specific messages for the patient or for the family's role in fall prevention (Haines, et al., 2011; Hill et al., 2009).

In developing a program of education for older adults and their family member in the acute care setting, the theory of planned behavior, an individual health behavior theory may be beneficial, particularly when aligned with social support theory. VonDras \& Madey (2004) studied 290 survey respondents to explore the theory of planned behavior and social support influences on health goal attainment. Participants developed their own health goals and proceeded to complete survey tools to measure the relationships of all aspects of the theory of planned behavior and social support as a 
predictor of successful attainment of their goals. All aspects of the theory of planned behavior were found to correlate with intention. The study also found a strong correlation to suggest that the emotional and instrumental social support by family or friends provides influence on behavioral intent around health goal attainment and may overcome motivators to follow perceived subjective norms.

The theory of planned behavior predicts deliberate behavior and has been used extensively in the healthcare field (Edberg, 2007). Ajzen (1991) provides a comprehensive review of the theory of planned behavior which is reviewed here. Importantly, the theory of planned behavior describes intention as the combined result of three elements: the individual's attitudes, subjective norms, and perceived behavioral control. An individual's attitude to behavior is, to some degree, valued either positively or negatively and is determined by behavioral beliefs and the subjective likelihood that the behavior will produce a given result. Subjective norm is the perceived social pressure to perform or not perform the behavior and is determined by normative beliefs, where the prominence of the norm and willingness to comply are of importance. Perceived behavioral control consists of the individual's perception of his/her ability to perform the behavior and is determined by control beliefs, which are factors that can facilitate or hinder performance of the behavior. If these three elements are generally positive, the individual will have the intention to perform the behavior but if the behavior is beyond the individual's control the behavior does not occur and perceived behavioral control thus has a direct impact on behavior. 
While no studies were reported using the theory of planned behavior for studying patient's fall prevention behavior in the hospital setting, findings from studies reviewed closely align with the theory's three determinants which influence intention to perform a behavior; attitude toward the behavior, subjective norms, and perceived behavioral control (CDC, 2005; Currie, 2008; Hitcho et al., 2004; Tzeng, 2010; Krauss et al., 2007; Carroll et al., 2010; Bates et al., 1995; Tzeng, 2010; Kloseck, Crilly, \& Gibson 2008; Yardley, Donovan-Hall, Francis, \& Todd 2006; Carroll, Dykes, \& Hurley, 2010; Tzeng \& Yin, 2009).

Social support theory and the quality of one's social support has also been studied extensively in the health care field and found to be a powerful factor for individuals meeting health related goals (VonDras \& Madey, 2004). Social support theory identifies how interpersonal relationships can influence the health behavior of others in both a positive or negative manner. Rook (1994) identified three forms of social support developed from studies of older adults which may have an impact on the older adult's health behaviors. These three forms of social support are categorized as emotional (provision of empathy and reassurance), instrumental (providing aid or services), and informational (providing advice and information). Rook (1994) also reviews the concept of social control which involves an important social member using persuasion and monitoring to encourage preventative health related behaviors and to not engage in risk taking health behaviors.

Although not directly measured, major concepts from the theory of planned behavior and social support theory provided the basis for the conceptual framework that 
guided the study (see Appendix A). As depicted in the model, the patient enters the hospital with beliefs about the likely impact of behavior, normative expectations, and factors that help or hinder behavior that prevent falls as well as social support from family. After admission to the hospital, the patient and family view the video on fall prevention. This educational intervention is expected to influence the beliefs about the likely impact of the behavior, beliefs about normative expectations, and beliefs about the factors that help or hinder behavior as well as social support in an attempt to increase intention to follow the falls prevention protocol. It was anticipated that fall rates in those patients who have viewed the video with family would be lower than patients who have not viewed the video and received information about fall prevention through a brochure.

\section{Purpose of the Study}

A gap was found in the availability of evidence based falls prevention education for the hospitalized adult patient and no clearly identified role for the family when educated; however there is some evidence that a multimedia delivery of education may improve knowledge and outcomes. The data and literature on falls is predominately focused on the older adult and expertise from health promotion literature encourages a clear target population when designing messages to change health behaviors (Edberg, 2007; US Department, 2004; US Department, 2005).

Therefore the broad long term goal of this study was to reduce rates of fall and falls with injury in the older hospitalized adult. The specific aims were to: 
- develop an evidence based video for the older hospitalized adult and family support person, based on the theory of planned behavior and social support theory

- increase the patient's knowledge of fall risk and behavioral intent to follow fall prevention strategies

- improve the family support person's knowledge of fall risks and their role in supporting the patient in behaviors that prevent falls in the hospital Specifically the study attempted to answer this question:

Are falls and falls with injury rates decreased in older adults when patients and family support are provided an educational video on falls prevention based on the theory of planned behavior and social support theory?

\section{Section II: Review of the Literature}

\section{Introduction}

Identification of the gap in availability of evidence based falls prevention education lead to a review of the literature guided by the theory of planned behavior. The intent was to find some evidence to develop messages for patients and families to improve compliance with fall prevention strategies.

The literature review is organized to present evidence related to risk factors associated with falling for older hospitalized patients, evidence related to insights from patients and caregivers views' on fall prevention, and studies previously published on fall education prevention for older hospitalized patients. The literature review is then synthesized to craft educational messages for the patient and family within the framework 
of the theory of planned behavior and social support theory (See Appendix B for the review of the literature table).

\section{Factors Related to Risk of Falling When Hospitalized}

Patients who require hospitalization are in varied states of dependency for care and at differing levels of self care ability. Patients of all ages have been found to fall while on an inpatient unit. However, in a study of 183 falls of older adults in one academic medical center, $85 \%$ occurred in the patient's room, 59\% during the evening and nighttime, 19\% during ambulation, and 50\% related to toileting (Hitcho et al., 2004). Central nervous system medications were administered to $58 \%$ of those who had fallen and $56 \%$ received vasoactive medications within 24 hours of falling (Hitcho et al., 2004). Limitations of this study included the potential bias which may result from one researcher determining themes within narrative data of hospital incident reports and results are not necessarily generalizable beyond the study site.

In a retrospective cohort study, Krauss et al. (2007) examined 7,082 falls in nine Midwestern hospitals to identify circumstances for falls and injuries. Of the non academic hospitals included in the study, a higher incidence of injury from falling was associated with increased age, falls in the bathroom, and falls which occurred in unassisted patients. This study may offer some insight to risk factors as the use of multiple hospital sites, even though in the same hospital system, and sample size strengthened the ability to generalize these results.

Toileting needs has been reported in the literature as a risk for patient falls. In a qualitative retrospective study of 547 falls incidence reports from four units in a hospital 
Tzeng ( 2010) found that $45 \%$ of falls were related to toileting and occurred when the patient was on the way to the bathroom from the bed or chair or on the way back to bed or chair from the bathroom. Because the consistency in data categorization of this qualitative study was achieved through use of only one researcher review, bias might be suspect. The need to toilet, with an associated loss of balance and unexpected weakness, were causes reported by 9 patients who had fallen within 48 hours of being interviewed (Carroll, Dykes, \& Hurley, 2010). Participants in this study also verbalized that they were reluctant to bother the busy nursing staff to assist them in toileting. These studies provide some evidence of toileting while unassisted as a risk factor for older adult falls in the hospital.

In a retrospective case-control study of 62 case control pairs, Bates et al. (1995) found a significant correlation between confusion and multiple comorbidities with falls injuries in one hospital setting. In a retrospective descriptive study of the influence of mental status on 1017 patients who had fallen, Tzeng (2010) found a statistically significant association between impaired mental status and severity of fall injury. Findings of the study reported $34 \%$ of these falls were associated with impaired mental status and statistical significance was found for impaired mental status for the more severe falls injuries. This study was conducted in one hospital but did include six different units within the hospital, allowing for the sample to represent differing patient diagnostic populations.

Other factors that may present as risk factors for falling were reported in the studies reviewed. Of 183 patient falls, Hitcho, et al. (2004) reported $29 \%$ of patients used 
an assistive ambulation device at home but only $6 \%$ were using a device when the fall occurred. In a qualitative study Tzeng \& Yin (2009) interviewed 91 patients in a home care setting after discharge from the hospital. Patients in this study reported availability of ambulatory devices, clear pathways in the room, timely answering of call bells, and bed height to be factors putting them at risk of falling.

These studies suggest multiple risk factors are related to falls in a hospital. There is some evidence for patients being at risk while unassisted in their rooms and during attempts to ambulate and toilet. Patients with impaired cognitive status and multiple comorbidities may also be at higher risk of falling in the hospital. Patient engagement in prevention may be hindered by attitudinal social norms related to not wanting to bother the nurse for assistance. Environmental factors also play a role in the patients risk for falling.

\section{Insights from Patients and Caregivers on Fall Prevention}

Two qualitative studies provide insight into patients' views of fall prevention education and messages. Tzeng \& Yin (2009) utilized a survey tool and visiting trained health care providers to collect data from 91 home health patients discharged from affiliated hospitals. Interviews were obtained within 30 days of discharge from a hospital. Information was elicited on the patients' opinions and observations regarding the fall prevention program received during their recent hospitalization. More than half of the patients in this study did not believe the fall-prevention program they received during hospitalization was adequate. Specifically they criticized beds being left in high position, insufficient fall prevention education, lack of ambulatory devices, cluttered 
rooms, need for increased monitoring, timely answering of call bells, and lack of physical therapy. They recommended a well designed education program with visual cues that engaged the patient and for nurses to offer more frequent repetition of fall prevention messages.

Patient focus groups provided the venue for a qualitative study by Yardley, Donovan-Hall, Francis, \& Todd (2006). In this study conducted in the United Kingdom, community dwelling older adults $(N=66)$ were asked about their perceptions of fall prevention advice and suggestions for designing communications to encourage older adults to practice fall prevention strategies. While these older adults agreed to the value of falls education, they related that they may not heed all of the advice and that some of these older adults believed the messages were for the disabled and not for them. Some participants perceived the messages to be authoritarian and a threat to autonomy and dignity. There was a recommendation by the participants to create messages that relay positive suggestions. The researchers debated whether these findings may indicate a need for increasing messages on the reality of older adults' vulnerability to falling.

Nurses $(N=23)$ and nursing assistants $(N=19)$ were interviewed using a focus group design to elicit views as to why patients in acute care hospitals fall and how falls might be prevented (Dykes, Carroll, Hurley, Benoit, \& Middleton, 2009). The researchers developed two categories, knowledge/communication and capability/actions which link facilitators and barriers retrieved from the interviews. The outcome data included the need to facilitate such areas as access to individual risk information for caregivers as well as patients and families, and strategies to overcome barriers such as 
patients not following instructions. While the sample size was small the interviewees represented four hospitals with differing characteristics.

These qualitative studies provide some insight to how patients and caregivers view the problems with falls prevention programs and the messages to prevent falls. Some patients are not impressed that current message designs convey how they are personally susceptible to falling and may even be perceived negatively as a threat to dignity. Some congruence may exist as nurses see patient noncompliance with prevention strategies as a barrier to preventing falls and patients interviewed requested increased frequency of reminders from nurses about fall prevention.

\section{Research on Patient and Family Fall Prevention Education}

In a three group randomized control Australian study, Haines et al. (2011) found no significant differences in fall rates between patients in a control group who received no specific education, patients in a treatment group who received multimedia education and a one on one follow-up with a health professional, and patients in a treatment group who received only the multimedia education. However, findings in this study did result in a significant difference in fall rates between cognitively impaired patients and those who were cognitively intact. The cognitively intact patients in the treatment group who received multimedia education with a one on one follow-up by a health professional experienced fewer falls than the cognitively intact patients in the treatment group receiving only multimedia education. Participants in the two intervention groups received content and progressive education based on the health belief model. 
This study provides some evidence for multimedia education with one to one follow up for cognitively intact patients as compared to a materials only group and control group. A power analysis was calculated and a total sample of 1206 patients allocated to control group $(N=381)$, materials only group $(N=424)$, and complete program group $(N=401)$ met the desired sample size. However, the setting of the study was two hospitals in Australia with sample subjects from both acute and subacute care units. The method allowed a week for one to one follow up by the health worker to review learning and set patient specific goals, possibly a reflection of the population which included a subacute level of care. The time spent individually with a patient for one to one follow up ranged from 20 to 36 minutes per patient. This method may not be feasible in hospitals with resource limitations and lengths of stay of less than one week.

In a randomized two group Australian study, with a quasi-experimental control group, Hill et al. (2009) compared the effect of falls prevention education delivered by DVD format or written format to no education, both of which were based on the individual health belief theory, the Health Belief Model. Following falls prevention education a custom designed survey measured patient's knowledge of risk of falls, perception of falls epidemiology, knowledge on prevention of falls, and confidence to follow falls prevention strategies. While both methods of education created higher numbers of desired responses to the survey compared to the control group, the DVD method of education delivery was found to produce statistically higher levels of confidence, motivation, and engagement in self-protective strategies than participants receiving education through written material. 
In this Hill et al. (2009) study, comparison is provided between a control group of 122 patients receiving no specific falls education to a group of 49 patients who received education through a DVD, and a group of 51 patients who received education through written material. While the study provides some evidence for multimedia delivered education, limitations of the study include generalizability related to sample size and lack of power analysis.

In a cluster randomized study, Dykes et al. (2010) utilized an information technology fall prevention tool kit which included a patient/family education intervention, the Morse Fall Scale risk assessment, a communication poster of the patient's fall risk, and a tailored patient fall prevention plan to decrease patient falls on study units in four United States hospitals in urban areas. The control group of 5104 participants received usual care and the intervention group of 5160 participants received a fall prevention patient specific fall prevention plan based on data from the Morse Fall Scale score entered into a health information technology system. The health information technology system then gave the nurse specific outputs for the communication poster over the patient's bed, a tailored plan of care, and a handout to give to the patient and family for fall prevention education. Findings included a significantly lower fall rate for intervention units and an even higher significance in reduction of falls in patients over age 65. While the sample size met power analysis requirements, the use of several fall prevention interventions does not allow the identification of the most effective intervention for the prevention of falls. Also, the health information technology was organizationally developed for this purpose. 
Only two studies were found comparing educational methods for the hospitalized patient each using a health behavior framework in designing the content of the education to reduce falls in hospitals. These research studies provide some evidence for the use of multimedia patient education as compared to written education material for cognitively intact older adults; unfortunately both were Australian studies limiting usefulness of the sample and the intervention due to health care organizational and cultural differences. However, support for use of a health belief model to guide educational program development is strengthened by these studies.

\section{Designing a Falls Prevention Patient and Family Education Plan}

The theory of planned behavior and social support theory was utilized to guide the development of a patient and family education plan. VonDras \& Madey (2004) conclude the theory of planned behavior components and social support by close family or friends offer an integrated model for health interventions. Therefore the education plan was designed to offer the patient and family instruction related to the three determinants of the theory of planned behavior. Family members were provided messages on their role to provide emotional and instrumental support to assist the patient to follow risk reduction strategies.

According to the theory of planned behavior the intention to perform a behavior is predicated on what and how strong the motivational factors are that influence that behavior (Ajzen, 1991). There are three independent determinants within the theory of planned behavior which influence intention to perform a behavior; attitude toward the behavior, subjective norms, and perceived behavioral control. (Ajzen, 1991; Edberg, 
2007). While no studies were found using the theory of planned behavior for studying patient's fall prevention behavior in the hospital setting, the findings from studies reviewed may indicate how these determinants are relevant in the context of a falls prevention education program for patients and families.

For patients to develop a healthy attitude toward using fall prevention strategies during hospitalization they need to understand the prevalence, adverse consequences, and risk factors related to falling. Some research suggests that older adult patients in the hospital are at higher risk of falling related to increased age, loss of balance and weakness, medications, cognition, toileting, time of day, ambulating unassisted in their rooms, environmental factors, and the existence of multiple comorbidities (Hitcho et al., 2004; Tzeng, 2010; Krauss et al., 2007; Carroll et al., 2010; Bates et al., 1995; Tzeng, 2010; Tzeng \& Yin, 2009).

Kloseck, Crilly, \& Gibson (2008) reviewed literature to explore the possible role of personality theory related to behavioral risk factors that may contribute to a patient falling and healthy attitudes toward fall prevention strategies. These authors reviewed factors such as personality traits which perpetuate risk taking behavior. This risk taking personality trait may contribute to those same individuals, as they age, to take risks when they also have a normal aging decline in the ability to attend. These factors may lead to a higher likelihood of falling. In such cases, these patient attitudes toward falling would be to take the risk, as their previous experiences may not have been with negative outcomes, but now with related inability to attend, leads to a fall. Similarly, some older people do not believe falls education is relative to them as they see this education is only for the 
disabled person (Yardley, et al., 2006). This belief would interfere with a patient's attitude for being at risk of falling while in a hospital.

Educational messages to promote healthy attitudes to comply with fall prevention strategies should be considered to adequately portray the risks and adverse consequences that are realities when older patients fall. These messages should include such information as falls being the leading cause of injury death (CDC, 2005) and the most frequently occurring adverse event in hospitals (Currie, 2008). The evidence that falls with injury result in a longer stay in the hospital (Bates et al. 1995; Wong et al., 2011) should also be included. Providing the strategies to alleviate such risk factors as falls related to toileting and medications should give the patient a sense of control over these risk factors. Messages regarding the use of evidence based guidelines and resultant reduction of hospital based falls would be a positive message of hope to promote a positive attitude for compliance. Family members should be educated on their role to assure proper foot wear that is slip resistant and to insist that the patient does not get out of bed unless they have the hospital slip resistant socks are worn to ambulate and do so with assistance. Families should understand that they can influence the patient to avoid taking risks and follow prevention strategies.

Subjective norms as a determinant of the theory of planned behavior may also be found in the literature reviewed. For patients in an acute care setting, even though the standard of care is to instruct the patient to use the call bell prior to getting up, there is evidence illustrating that patient's do not consistently follow the instructions because they wish to avoid bothering the busy nurse (Carroll, Dykes, \& Hurley, 2010). Patients 
perceive asking for assistance as socially unacceptable when that person is busy. In the interviews by Yardley et al. (2006) older people viewed falls prevention messages as a threat to their autonomy and independence. Subjective norms in this case dictate a high regard for remaining independent.

Carroll, Dykes, and Hurley (2010) recommended that patients need to be educated by the nurse to assure them that patients are not a bother and assisting them is the work for the nurse, regardless of perceived availability. This is a crucial message around perceived social norms that must be included in the education and family support messages provided to the patient around this subjective norm. Messages regarding the hospital as no place for risk taking behaviors is necessary. This information should be framed as a positive message of autonomy in preventing the patient's own fall injury. Encouraging this new subjective norm will be a role for the family in supporting patients to call for the nurse, be patient, and not take risks.

The third determinant of the theory of planned behavior is perceived behavioral control. Among the studies reviewed, patients reported environmental risk factors which are impediments to their safety related to falling in a hospital and not within their control. Availability of ambulatory devices, cluttered rooms, beds left in a high position, time delays in nurses answering call bells, and lack of pull bars were reported as barriers to their ability to be compliant with falls prevention strategies (Hitcho, et al., 2004; Tzeng \& Yin, 2009). For patients to believe there are no impediments to their ability to practice fall prevention strategies, these barriers must be understood and acted upon and patients must be given the permission to ask hospital staff to remove the barriers. 
Education related to perceived behavioral control must put the patient as captain of their own destiny. Messages to assure the patient that hospital personnel wish to provide them with a safe environment are necessary. The message that access to ambulatory devices, a clean and clutter free room, and a bed that is always in low position when the patient is not receiving treatments are to be expected by the patient. Instructing the patient or family to have staff attend to these environmental necessities before leaving the room is expected of them and not viewed as demanding. Family members must understand that before they leave the room they must assure the environment is clear of hazards and personal devices are within reach, and they must also remind the patient why this is important to preventing a fall.

There is evidence supporting education delivery in a multimedia format. However the setting for both of the studies using multimedia formats was Austrailia, which prevents the use of the same multimedia program due to cultural and linguistic differences between the Australian and American population (Hill et al., 2009; Hitcho et al., 2004). While a commercially prepared falls education video is available (Envision, 2012), this video does not include educational messages for the family or support person regarding their role assisting the patient to prevent falls while in the hospital.

\section{Conclusion}

Available literature supports using the theory of planned behavior and social support theory to guide the development of a falls prevention education program and social support of family to influence patient's compliance with fall prevention strategies. 


\section{Section III Method}

The study utilized a quasi-experimental two group design with a Phase 1 comparison group and Phase 2 intervention group. The study sought to determine if an evidence based falls prevention video for older adult patients and their families with the patient reduced falls and falls with injury. Both Phase 1 and Phase 2 groups received usual care for all patients as defined by the study unit protocols on fall prevention. This included unit orientation, a falls education brochure, and a fall risk assessment tool completed on every patient every twelve hours to determine each patient's risk for falling. Patients then receive fall prevention interventions based on their fall risk score of high, medium, or low. These interventions may include yellow slip resistant socks, yellow arm bands, bed alarms, and staff remaining in the bathroom with patients while toileting.

Samples of convenience were used during both phases of the study. In the first Phase comparison group falls and falls with injury in the consented patients were measured. In the second Phase intervention group falls and falls with injury in consented patients were measured. The intervention group was shown an evidence based falls prevention education video, with education messages for patient and family, via the television system in the patient's hospital room. The video intervention was in addition to usual care for fall prevention on the study unit, with usual care including the fall prevention brochure given to every patient. The video content based on the theory of planned behavior and social support theory was shown following consent of the patient and family when available. After viewing the video a Registered Nurse used teach-back 
with the patient. Phase 1 study period was October through December of 2012 and Phase 2 study period was from February through April of 2013.

\section{Hypothesis}

The study tested the following hypothesis:

Hypothesis - A group of older adult cognitively intact patients receiving an evidence based falls prevention video and targeted family support will have fewer falls and falls with injury than a control group receiving usual care in the form of a written brochure.

\section{Setting and Sample}

The study was conducted in a 36 bed adult medical acute care unit in a 238 bed community hospital. The study unit averages 274 admissions and transfers to the unit per month and of these admissions and transfers, 194 patients are 60 years of age and older. This rural designated hospital is part of an 11 hospital integrated healthcare delivery system in the Mid-Atlantic portion of the United States. The patient population on this unit includes non telemetry medical patients and a small percentage of oncology patients. The unit nursing care is provided by Registered Nurses, Patient Care Technicians, and Registered Nurse Case Managers who received education on the content of the video and study methods. This unit had been chosen in 2011 to pilot implementation of falls reduction strategies as outlined in the ICSI guideline "Prevention of falls (acute care). Health care protocol” (ICSI, 2010; Degelau, et.al, 2012). After moving to a new replacement facility the organization experienced an increase in fall rates in the acute care units. The unit was chosen to study fall reduction strategies as it had the most 
opportunity for reduction at that time with a 5.93 total fall rate and 1.50 falls with injury rate for the year 2011. Therefore, this current study was an extension of implementing the protocol strategies for fall reduction when a gap in availability of falls prevention education for acute care was found.

The organization is the primary health care provider for approximately 215,000 residents with over 14,700 annual admissions and a 47\% Medicare payer mix. There are three universities and a community college within the service area and three retirement communities. Cultural diversity of the population served is evidenced by the organization providing over 3500 Spanish speaking interpreter calls during a previous twelve month period in addition to employed Spanish speaking interpreters.

A sample of convenience served as the study population for the intervention and comparison groups for the study. The criteria for inclusion in Phase 1 and 2 of the study were as follows:

1. Patients admitted or transferred to acute care medical unit, $3 \mathrm{~W}$

2. Adult age 60 and over

3. Patient's with or without a family support

4. English or Spanish speaking

5. Consent to participate

6. Absence of diagnosis related to dementia, confusion, Alzheimer's, or other cognitive disability 


\section{Interventions}

The treatment intervention consisted of the patient, and family member when available, viewing an evidenced based video on prevention of falls in the acute care setting. Evidence based messages for falls prevention were developed based on a review of the literature, the theory of planned behavior, and social support theory. The researcher collaborated with a professional communication and marketing team to develop message concepts and a content outline addressing the three determinants of the theory of planned behavior and social support theory for messages to guide family to support the patient in behaviors to prevent falls.

Development of the educational messages incorporated the social marketing planning process (Appendix B) to develop falls prevention messages and communication strategies in the creation of an evidence based falls prevention video for the target population (US Department, 2005). Horsburgh (2003) and Russell \& Gregory (2003) described the need for purposive sampling in order to obtain relevant qualitative data. Therefore messages were pretested by reviewing key messages from the content outline presented in a power point format with three English speaking patients on the study unit who met the inclusion criteria. The patients interviewed to pretest the messages included one male who had fallen while on the study unit, one male who had not experienced a fall, and a female who had fallen and injured herself prior to admission. No Spanish speaking patients were available for interview during the time available for pretesting messages. 
Pretesting serves to determine how the intended audience may react to different concepts or messages (US Department, 2005). Russell \& Gregory (2003) discussed the ability to review already published qualitative data which focused on the subject under study when determining sample size for qualitative investigations. Such published data has been presented in the literature review, was evident in the pretesting with patients, and allowed for a small sample size for the purpose of determining reactions to messages. The content outline used to produce the video was edited based on the pretested patient's responses to these power point messages and is available as Appendix D. The final content outline was reviewed by the organization's Cultural Coordinator who found no messages that may conflict with cultural norms.

The video delivers messages from the content outline by a narrator, two Registered Nurses, and a family member based on the theory of planned behavior and social support theory. Review of previous falls in the organization failed to identify a patient who would have been included in the video. A family member identified as an advocate for a current patient at risk of falling was approached and agreed to participate. This family member had previously experienced the loss of a parent due to a serious injury and eventual death related to a fall in another facility. The family member's parent had gotten up without assistance, believing she could walk, fractured a hip, and died within 3 weeks.

The content of the video addresses educating the patient to prevalence and consequences of a fall and risk factors associated with an acute illness which has required hospitalization. Education on risk factors of medications, weakness, urgency to toilet, 
older age, and failure to call the nurse before attempting to ambulate targets the patient's attitude to behave in ways to prevent falling. The messages contain prevalence and consequences of falls in hospitals, such as hip fracture injuries, head injuries, and death. Content also includes messages that the nurses in the organization do not want patients to fall and they are never "bothered" when a patient rings their bell, or when the patient asks for their assistive devices to be moved closer. Patient control messages target the patient's autonomy and control to keep themselves safe by not taking unnecessary risks while hospitalized, using their call bell, and assistive ambulatory devices if ordered. Family member messages center on their role to remind the patient of prevention behaviors that they must follow and support the patient in performing prevention behaviors to meet the goal of no falls while in the hospital.

During Phase 2, the Registered Nurse or Patient Care Technician activated the video for consented patients and family members. The video was shown over the television in the patient's room. Upon completion of the video a Registered Nurse was to ask the patient to describe one thing that the patient learned that they can do to prevent falling (teach-back), ask the patient if they have questions, and document that the video was viewed, by whom, and that teachback occurred. The Registered Nurses were educated to this process prior to Phase 2 study period and reminded in staff meetings and weekly emails by the unit manager.

Teach-back is a recommended best practice to assure patient's understanding of the health education content being delivered and utilized in this study for its efficiency as compared to that of the one to one health counselor follow up method by Haines et.al., 
(2011). The Institute of Healthcare Improvement endorses the use of teach-back and provides a "tool kit" for instructional purposes (IHI, 2013). The National Quality Forum also endorses teach-back as a safe practice when obtaining informed consent (NHQ, 2013) and Kripalani, Bengtzen, Henderson, \& Terry (2008) utilized teach-back in a study when obtaining informed consent with low-literacy populations and found it to be a "preferred method" (p. 17). Nurses have also designed studies around the use of teachback with positive results to improve the patient's understanding at discharge (Kornburger, et.al., 2013) and self care in heart failure patients (Howie-Esquivel, White, Carroll, \& Brinker, 2011).

The Phase 1 comparison group received usual care in the form of a brochure given to all patients and families to read (Appendix E). This brochure was developed by two of the organization's Registered Nurses as a project for Clinical Ladder progression and based on the same review of the literature as utilized for the treatment video. Unit Registered Nurses were to provide the brochure on admission to all patients for review by the patient and document in the patient's electronic medical record that the brochure was given to the patient. The Registered Nurses were educated to this process prior to the Phase 1 study period and reminded in staff meetings and weekly emails by the unit manager.

\section{Variable and Measurement}

Dependent variables measured are falls and falls with injury collected by review of fall huddle reports and compared to an electronic report from the medical record documentation. The study data measures include baseline participant characteristic data, 
participant lengths of stay (LOS), participant falls, and participant falls with injuries. Participant characteristics collected and utilized for analysis includes age, gender, race, and primary language. Measurement definition of a fall and fall with injury follows the ICSI "Prevention of falls (acute care). Health care protocol" (ICSI, 2010) definition below:

Falls: a fall is defined as any unplanned descent to the floor.

Falls with injury: categorized on a 5 point scale:

1. No apparent injury

2. Minor: bruises or abrasions as a result of the fall

3. Moderate: an injury that causes tube or line displacement, a fracture, or a laceration that requires repair

4. Major: injury that requires surgery or a move to intensive care unit for monitoring a life-threatening injury

5. Death

For study purposes, fall rates were defined as falls in category 1 and falls with injury rates to include categories 2 through 5 .

Demographic and length of stay data were collected from the participant's medical record by electronic query.

A paper fall huddle report (see Appendix F) and electronic queries of nursing documentation from the patient electronic medical records is used by the organization in which the study took place to capture patient falls. The fall huddle report form is completed immediately after a fall when the nursing staff and manager "huddles" to 
assess causes for the fall and update the plan of care to prevent future falls. The huddle reports are sent by personnel in the unit where the patient fell to the Chair of the Falls Steering Committee and then to the Quality and Risk Department to correlate with the electronically queried falls report to assure all falls are captured. This data is then categorized as a fall or fall with injury as based on the definitions outlined. Data were reviewed from the fall huddle reports of two patient falls which occurred during the study for analysis of potential trends.

\section{Research Procedures}

The initial design used the trained unit Registered Nurse Case Manager and Charge Nurses to attempt consent on patients meeting inclusion criteria. A daily electronic report of all patients currently on the study unit was developed and included the patient name, room location, age, and current status of consent. Review of the report was to occur between the Registered Nurse Case Manager and Charge Nurse to validate patients' current cognitive function. A review of the consent process after the first month of Phase 1 found that patients meeting study criteria were not being approached for participation in the study. It was determined that in order to consistently allow more patients meeting study criteria to have opportunity to participate in the study dedicated staff would be necessary to systematically attempt to consent patients.

A decision to utilize trained Patient Care Technicians to consent participants was implemented in December. The trained Patient Care Technicians were scheduled for several hours per day, Monday through Friday, for the remainder of the study in order to dedicate time to the consenting process. Past history of cognitive diagnosis was added to 
the daily electronic report. The Patient Care Technicians utilized the electronic report and reviewed cognitive status of the patient's without prior cognitive diagnosis with the Charge nurse prior to consenting patients meeting inclusion criteria for the study.

Consenting of patients did not occur on the weekends for both Phases of the study due to resource limitations.

During Phase 2, the falls prevention video was initiated by the unit Registered Nurse or Patient Care Technician. The unit's Registered Nurses were educated to initiate the video when notified of completion of informed consent and to document this intervention in the medical record. However, to streamline the procedure, the Patient Care Technicians began initiating the video following consent procedures and notifying the patient's assigned Registered Nurse to discuss the video with the patient. This change was implemented midway through Phase 2.

\section{Ethics and Confidentiality}

The informed consent forms utilized in the study for intervention and comparison participants is available for review in Appendix $\mathrm{G}$ and Appendix $\mathrm{H}$ which contain statements of no known risks for participants and possible benefits to the participant during the study. Approvals for the study were obtained from the Investigational Review Boards of the study organization and the University of Virginia where this researcher is a Doctoral student. Institutional Review Board approved the addition of trained Patient Care Technicians who were dedicated several hours per day (except on weekends) to consent patients meeting study criteria. Copies of these approvals are available in Appendix I. Patient level data will only be reported or published in aggregate to protect 
the confidentiality of staff and patients. No adverse events occurred during the study. There are no currently identified conflict of interest issues related to this study.

\section{Data Analysis}

All statistical tests were performed using SPSS software v. 21 by an employed University of Virginia PhD nursing student. Frequencies and means were calculated for sample characteristics. Phase 1 and Phase 2 groups were compared on demographic characteristics and length of stay variable using appropriate statistical tests such as the ttest and chi-square. Due to positive skewness of the length of stay variable, the Mann Whitney U test was used to compare mean ranks. Generally chi-square test was used to check differences for the delivery of interventions between groups. All statistical significance tests were set at $\mathrm{p}<0.05$. Fall and fall with injury rates were calculated per 1000 patient days. Effect size was calculated for strength of association using the Pearson $r$. Fall huddle reports for two patient falls during the study were analyzed for comparison of variables.

\section{Journal Submission}

The study will be prepared as a manuscript according to the Journal of Nursing Care Quality author guidelines and submitted for publication (Appendix J).

\section{Section IV: Results}

\section{Findings}

During the study Phase 1 and Phase 2, 1897 patients were admitted or transferred into the study unit setting. Of the 630 patients admitted or transferred to the study unit during Phase 1 , a small portion of patients consented to participate in the study $(N=100$, 
$16 \%)$ and a smaller portion of patients $(N=74,12 \%)$ declined to participate. The majority of patients admitted or transferred to the study unit during Phase $1(N=456$, $72 \%$ ) were either not eligible or consent was not attempted. In Phase 2 a similar portion $(N=92,16 \%)$ of the 565 patients admitted or transferred to the study unit consented to participate in the study and one forth $(N=143,25 \%)$ of the patients declined to participate. A little more than half $(N=330,58 \%)$ of the patients in Phase 2 were either not eligible to participate or for which consent was not attempted. Less than a fifth $(N=$ $17,19 \%$ ) of patients' family/significant others consented to participate in the study during Phase 2. A higher proportion of patients declined during Phase 2 which may reflect an increased number of patients approached to participate in Phase 2.

Demographic and length of stay characteristics between groups are summarized in Table 1 (Appendix K). Phase 1 control group $(N=100)$ and Phase 2 study group $(N=$ 92) met desired target group sample size of 30 that would provide $80 \%$ power to detect differences between groups (Wilson Van Voorhis \& Morgan, 2007). Statistical analysis revealed no missing data. There were no statistically significant differences in characteristics between groups.

There were no statistical differences in mean age between the groups, $t(190)=-$ $.095, p=.92$. Chi-square tests for association were conducted to determine whether differences between groups existed for gender, language, and race. The majority of the participants in both groups were female. In Phase 164 (64\%) were female and in Phase 2 group $56(61 \%)$ were female with no statistical differences found for gender between the groups $\chi 2(1, N=192)=0.20, p=.33$. Nearly all of the participants were English 
speaking in both groups with the exception of $1(1 \%)$ participant who spoke Spanish in the Phase 2 group. Because there were less than 5 participants who did not speak English, the Fisher's Exact Test was performed finding no statistical differences between groups based on language $\chi 2(1, \mathrm{~N}=192)=1.09, \mathrm{p}=.24$. The Yates's Continuity Correction Chi-square test for association was conducted for race given the smaller than expected count in races other than Caucasian. This test adjusts for drastic proportions of differences in samples (Vogt, 1999). A 2-level race variable (Caucasian vs. other) resulted in no statistically significant differences between the groups for race $\chi 2(1, \mathrm{~N}=$ $192)=1.09, p=.12$. The use of chi-square Mann-Whitney $U$ test for association revealed no statistical differences in length of stay characteristic between groups $U=$ $4,858, p=.25$.

Less than half $(N=42,42 \%)$ of consented participants in Phase 1 had documentation in their medical record that the falls prevention brochure had been provided. A similar number of consented patients in Phase 2 had documentation in their medical record that they received the falls prevention brochure $(N=44,48 \%)$. A review of the medical records of participants in Phase 2 indicated that a third of the sample $(N=$ $33,36 \%$ ) received both the falls education brochure and video. A fourth of the participants in Phase $2(N=24,26 \%)$ viewed the video and did not receive the falls education brochure. A small portion of participants in Phase $2(N=7,8 \%)$ had documentation of viewing the video with their family/significant other even though this represents less than half the number of family/significant others who consented to participate $(N=17)$. In total, patients who viewed the video during Phase 2 with or 
without receiving a brochure or having a family member view the video, accounted for more than two thirds $(N=64,70 \%)$ of the Phase 2 participants. The fidelity of the intervention of teach-back following the patient viewing the video was strong as the teach-back was documented as occurring in the majority of those who viewed the video $(N=60,94 \%)$.

Interestingly, in Phase 2, the majority (82\%) of participants received a falls education intervention (brochure or falls education brochure and video) while in Phase 1 less than half (42\%) of participants received a falls education intervention (brochure). There was a statistically significant difference between groups in the proportion of patients receiving any kind of falls educational intervention based on the study phase they were in, $\chi 2(1, N=192)=0.20, p<.001$. The effect size for this analysis $(\mathrm{Phi}=.41)$ was found to exceed Cohen's (1992) convention for a medium effect $(r=0.30)$.

Two falls occurred without injury during Phase 1 and no falls or falls with injury occurred during Phase 2. Because there were fewer than 5 falls, the Fisher's Exact Test was performed resulting in no statistical difference between groups by number of falls $\chi 2(1, N=192)=1.86, p=.270$. The effect size for this analysis $(\mathrm{Phi}=.10)$ was found to just meet Cohen's convention for a small effect $(\mathrm{r}=0.10)$. Results for falls and falls with injury rates were calculated based on 1000 patient days. Phase 1 fall rate was 6.01 (2 falls/333 patient days x 1000 patient days). Phase 2 fall rate was 0.0 ( 0 falls/347 patient days $\mathrm{x} 1000$ patient days). The low number of falls during both Phases did not allow for a statistical difference between the Phase 1 and Phase 2 groups nor the ability to run any 
statistical analysis for differences between rates. No falls with injury occurred in either Phase 1 or Phase 2.

Comparison of Post-Fall Huddle Forms between the patient falls revealed falls occurred within 2 and 5 hours following administration of opiates for pain and occurred when the male patients attempted to toilet without calling for the nurse. Nursing had performed rounds on each patient within an hour of the patient's fall. The risk assessment tools scored one patient as a moderate risk and the other as a high risk, with one patient having a history of a fall at home within the past six months. Only one of the fall patients had documentation of receiving the fall prevention brochure. Neither fall resulted in an injury.

\section{Discussion}

The purpose of the study was to reduce falls and falls with injury in the older hospitalized adult. Viewing of a falls prevention education video by the patient and family support member was intended to increase the patient's knowledge of fall risk, influence their behavioral intent to follow fall prevention strategies, and improve understanding by the family support member on their role in supporting the patient in fall prevention behaviors. The study hypothesized that a group of older adult cognitively intact patients receiving an evidence based falls prevention video and targeted family support would have fewer falls and falls with injury than a comparison group receiving usual care in the form of a written brochure. Although the hypothesis was rejected there may be clinically significant findings related to providing evidence based fall prevention education to patients based on the theory of planned behavior. 
No statistical evidence was found to support the study hypothesis due to the small number of patients with a family support consenting and viewing the evidence based falls prevention video $(N=7)$. The small number of falls occurring during either Phase of the study prevented planned statistical analysis for comparison of the two study Phase groups.

While the study did not reinforce social support theory as a component for the theoretical model (Appendix A), the study may indicate the benefit for use of evidence based messages with patients based on the theory of planned behavior when measuring and comparing fall rates from a clinically significant improvement aspect. The clinical significance derives from findings that the majority of patients $(82 \%)$ in Phase 2 received the brochure and/or video fall prevention education with messages based on the theory of planned behavior and fell less frequently (0 per 1000 patient days) than patients in the Phase 1 compare group. Phase 1 compare group participants received a falls education brochure less than half the time (42\%) and fell more frequently (6.01 per 1000 patient days).

Acute care hospitals are today benchmarked on the quality of their falls prevention program by their falls and falls with injury rates. Indeed, the standards of the American Nurses Credentialing Center's Magnet Recognition Program ${ }^{\circledR}$ set the expectation for hospitals to outperform nationally benchmarked mean comparisons for nurse sensitive indicators such as fall rates (ANCC, 2008). The National Database of Nurse Sensitive Indicators (NDNQI) is one source of national benchmark data for nurse sensitive indicators and used by many hospitals. NDNQI develops rank comparisons on 
falls and falls with injury rates to like units from the database for member hospitals (NDNQI, 2013).

The comparison of rates between Phase 1 brochure group and Phase 2 brochure and video group holds clinical significance when comparing a Phase 1 fall rate of 6.01 to a Phase 2 fall rate of 0 . Of significance to this study, the NDNQI mean fall rate for the 746 like units for comparison to the study unit in the fourth quarter 2012 (Phase 1) was 3.81 (S.D. 2.13) as compared to the Phase 1 participant fall rate of 6.01 (approached the $90^{\text {th }}$ percentile performance for this quarter benchmark). The NDNQI mean fall rate for the first quarter 2013 (Phase 2) for 768 like units for comparison was 3.60 (S.D. 2.06) as compared to the study unit's participant rate of 0 (below the $10^{\text {th }}$ percentile in comparison group). While there is no evidence based on a statistical difference in fall rates between the groups, these national benchmark comparisons are important in light of the statistical differences and effect size between the groups in the percentage of patients who received any type of fall prevention education.

The statistical differences in the percentage of patients who received any type of falls prevention education between the Phase 1 and Phase 2 groups, $\chi 2(1, N=192)$ $=0.20, p<.001$, may corroborate previous study findings. Hill et al., (2009) compared DVD education, workbook education and a control group receiving no education. This study did not include a variable measure of falls or falls with injury, but rather measured the participants improvements in knowledge of falls and prevention based on messages using the Health Belief Model, another individual health behavior theory similar to the theory of planned behavior. Hill and colleagues surveyed the participants' knowledge on 
falls and fall prevention strategies following education by either a workbook or DVD. While the DVD group was found more likely to be motivated and engaged in fall prevention, both groups receiving either education method provided higher knowledge survey results than that of the control group $(p<.001)$. Phase 2 results of this current study indicate a high percentage of patients received the video education (70\%) as a targeted intervention and a statistically significant difference in the number of patients receiving any falls education between Phase $1(42 \%)$ and Phase $2(82 \%)$. Thus the lower fall rates in Phase 2 of this current study may be consistent with Hill and colleagues previous work where both the DVD and workbook method served to produce survey results for knowledge related to falls and fall prevention.

The current study findings for lower fall rates for older adults receiving falls prevention education followed by teach-back may also be consistent with previous research by Haines et.al. (2011). This previous study, a randomized 3-group trial, compared a video and written materials falls prevention education intervention with follow up by a health counselor, a video and written materials only intervention, and no specific falls education control group. The sample included participants 60 years of age and older, a diversity of patient populations, as well as cognitively impaired participants. After controlling for cognitively impaired participants, Haines et.al. (2011) found that fall rates were much lower in the cognitively intact group receiving video and written materials with a health counselor follow up (4.01 per 1000 patient days) than the video and materials only group ( 8.18 per 1000 patient days). The health counselor follow up in this pervious study was time intensive taking between 20 and 36 minutes per patient and 
study design allowed a week for this counseling to occur. Both intervention groups with cognitively impaired participants removed had lower fall rates than did the control group with cognitively impaired participants removed (8.72 per 1000 patient days).

During Phase 2 of this current study almost $70 \%$ of participants viewed a falls education video and a majority (94\%) of these participants received follow up by way of teach-back by the Registered Nurse. The resultant fall rate of 0 during Phase 2 compared to Phase 1 fall rate of 6.01 corroborates the Haines et.al., (2011) findings for fall rate reductions when patients viewed a video, were given a written workbook, and had follow up by a health counselor. While only a third of participants in Phase 2 received both the video and brochure, the current study results are consistent with Haines et.al., (2011) findings of a reduced fall rate when some type of follow up is introduced after the patient views the video. The teachback method following a patient viewing of the education video was designed as a proxy for the follow up intervention described by Haines et.al. (2011) in a manner less resource intensive.

Interestingly, implementing the falls education video in Phase 2 increased the number of patients overall who received some type of education; $82 \%$ received either the brochure alone or the brochure and the video, while in Phase 1 only $42 \%$ received the brochure only. The fidelity of patients receiving the brochure during Phase 2 was not so different $(48 \%)$ than during Phase $1(42 \%)$. Therefore there might be some association for patients in Phase 2 receiving falls prevention education by video (70\%), and teachback performed the majority of the time (94\%), with falling less frequently than patients receiving usual care including the brochure. Analysis revealed a statistically significant 
difference between these groups related to patients receiving falls prevention education and the effect size for this difference exceeded Cohen's (1992) convention for a medium effect. Coe (2002) when comparing effects size to the use of statistical tests states "Effect size emphasizes the size of the difference rather than confounding this with sample size" (p. 1). Ferguson (2009) defines effect size as a means to "estimate the magnitude of effect or association between two or more variables" (p. 1).

Although the small numbers of falls in either group hindered analysis of statistical comparison for falls between groups, the effect size met Cohen's (1992) convention of 0.10 for a small size effect. Durlak, (2009) discusses the need for researchers to evaluate the practical or clinical significance in the context of "the extent to which there has been a meaningful change in participants' lives" (p. 924). Durlak (2009) expands on this by instructing researchers to interpret the effect size in relation to how difficult an outcome is to obtain when evaluating clinical significance. An effect size of 0.10 with an outcome that is difficult to obtain may be of greater clinical significance than an effect size of 0.50 when the outcome is relatively easy to obtain or less critical to the health of participants (Durlak, 2009). Falls in the acute care setting have been a difficult problem to eradicate and at times devastating to the life of the older adult. Therefore this small effect size finding may be of clinical significance in the search for fall prevention interventions. This observation, in light of effect size and previous research findings, may support the use of multimedia education with teach-back over written material as an educational intervention to prevent falls. 
After reviewing the information from the huddle reports of the two patients that fell during Phase 1, it was clear that both patients' reported attempting to toilet prior to falling. This supports the research of Tzeng (2010) and Hitcho et.al. (2004) who found that toileting without assistance accounts for between $45 \%$ (Tzeng, 2010) and 50\% (Hitcho et.al, 2004) of patient falls. This message is included in the falls education brochure and video. These patients had also received opiates for pain within 5 hours of falling. Hitcho et.al. (2004) found that $58 \%$ of falls occurred in patients receiving central nervous system medications. The brochure and video contain messages regarding effects of new medications.

\section{Limitations}

In is important to note the limitations of this study. First, the study was conducted in only one unit in one acute care facility. The study needs to be conducted in different types of units in multiple health care organizations. Second, the sample size was too small to conduct the planned statistical analysis. The small sample size was likely related to the failure of nursing personnel to consistently perform and/or document interventions, and the difficulty in procuring consent from both patients and families. Third, the relatively short duration of the study was a limitation.

During Phase 1, staff nurses who functioned in their usual capacity of caring for patients were expected to consent patients. The expectation was unrealistic and thus, patients who met the criteria were not approached for inclusion in the study. During the final month of Phase 1 and during Phase 2, patient care technicians were trained to obtain consent from patients and families. Limited resources prevented providing support for 
obtaining consent 7 days per week and even providing additional support 5 days per week for several hours per day was a stretch to the budgeted resources. Additionally, no test of cognitive function was performed prior to consenting patients and therefore it is possible that participants may have been included in the study that had some confusion or cognitive impairment. Finally, patient care technicians found it difficult to obtain consent because family members were often not visiting with the patient at times the technicians were present.

In addition to the difficulty in procuring consent, the falls prevention interventions were not consistently documented. Despite the initial education program for the staff nurses, weekly email reminders, and reminders at staff meeting, interventions were not consistently provided to the patient and/or documented. Midway through Phase 2, patient care technicians who had consented patients were also directed to provide the patient's assigned nurse with a pink instruction document after activation the video. The instruction sheet was designed to remind the nurse to document and provide teach-back. Regardless of these consistent reminders and process changes, only 7 of the 17 family members who consented to participate had documentation of viewing the video. Investigators need to be cognizant of the resources required for obtaining consent from patients and families.

The relatively short duration of the study was another limitation. Data were collected from patients and families in one unit over a 3 month period for each Phase of the study. Perhaps this was not enough time to capture the impact of the video and brochures. 


\section{Implications for Future Research}

In addition to replicating the study in different types of units in multiple health care organizations over a longer period of time, there are other implications for research. Future research might also be conducted to determine if allowing family members of cognitively impaired patients to view the video with teachback and measure the impact of falls for these patients.

Both the members of ICSI (2010) and Currie (2008) identify need for multifaceted interventions to reducing falls in the hospital setting. Future research should be conducted not only to determine the impact of this new video on patient falls, but also to determine which combinations of interventions are most effective in preventing falls.

\section{Implications for Nursing Administrative Practice}

Although the hypothesis was not supported, there were fewer falls in the Phase 2 intervention group than in Phase 1 comparison group. Thus, nursing leaders should indeed continue to implement and evaluate falls prevention protocols that include video based education and teach-back. Performance improvement monitoring within the organization's other inpatient units as the video is implemented on all inpatient units will provide further opportunity to measure the video intervention. .

Implications for nursing leadership relates to the difficulty of implementing research based studies requiring consent of patients and consistency of documentation of intervention implementation. Systems and processes should be piloted and monitored prior to beginning the measurement period of a study in order to better hardwire the fidelity of the interventions, documentation of the interventions, and the processes for 
consent of participants. Time and resources should be allocated to develop and test such procedures in order to improve the power of the study findings. Boase, Kim, Craven \& Cohn (2011) interviewed nurses regarding their experiences delivering complex research intervention in a randomized control study; a review of the results indicated that nurses are challenged to implement research interventions due to time and competing demands of their patient needs. Additionally, when depending on documentation to collect data, there must be clear expectations on where and how this documentation occurs in the electronic medical record and monitored prior to study implementation. When clinicians do not document in the same manner electronic queries for auditing and measuring are flawed. Larger sample sizes would make it impossible to manually determine the fidelity of interventions.

As health care continues to be challenged to reduce costs and improve quality, it is imperative that as nurse leaders we develop effective and efficient ways to assure our patients are educated and motivated to follow behaviors that promote health. Theory and evidence based education videos with teachback may be a technological tool to enhance efficiency while also being effective. Further study of the model for this educational video could provide a standard of practice to develop messages and education for additional quality indicators where patients and families have some control or influence over those outcomes. 


\section{Appendix A}

Figure 1: Conceptual framework for an educational intervention of influencing intent to follow the fall protocol based on the theories of planned behavior and social support 
Figure 1. Conceptual framework for an educational intervention for influencing intent to follow the falls protocol based on the theories of planned behavior and social support

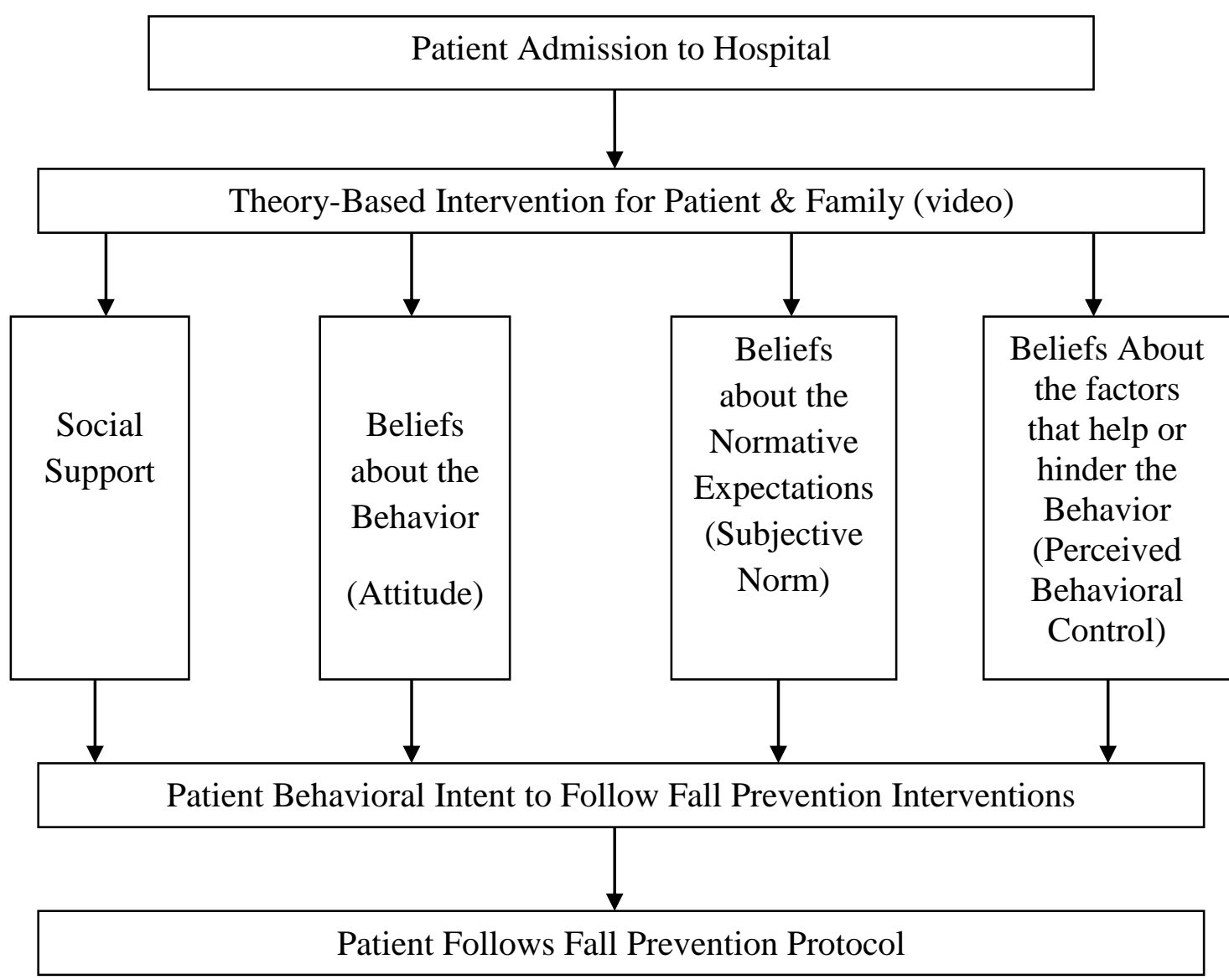

Figure 1. As depicted in the model, the patient enters the hospital with beliefs about the likely impact of behavior, normative expectations, and control over behavior as well as social support. The evidence based video is expected to influence these beliefs and prompt social support toward fall prevention behaviors. 
Appendix B:

Table 1: Description of Qualitative Literature

Table 2: Description of Quantitative Literature 
Table 1: Description of Qualitative Literature

\begin{tabular}{|c|c|c|c|c|c|c|}
\hline Author & $\begin{array}{l}\text { Purpose of } \\
\text { study }\end{array}$ & $\begin{array}{l}\text { Study Design: } \\
\text { Type of Design }\end{array}$ & $\begin{array}{l}\text { Rigor and } \\
\text { Validity }\end{array}$ & $\begin{array}{l}\text { Sample } \\
\text { description } \\
\text { and Number }\end{array}$ & Type of analysis & $\begin{array}{l}\text { Major findings and } \\
\text { implication }\end{array}$ \\
\hline $\begin{array}{l}\text { Carroll, Dykes, } \\
\& \text { Hurley } \\
(2010)\end{array}$ & $\begin{array}{l}\text { To explore the } \\
\text { patient's } \\
\text { experience of a } \\
\text { fall and to gather } \\
\text { information on } \\
\text { ways of } \\
\text { preventing falls } \\
\text { in acute care } \\
\text { hospitals. }\end{array}$ & $\begin{array}{l}\text { Qualitative } \\
\text { descriptive study } \\
\text { design } \\
\text { Investigators tape- } \\
\text { recorded } \\
\text { individual patient } \\
\text { interviews within } \\
48 \text { hours of their } \\
\text { fall while an } \\
\text { inpatient in an } \\
\text { acute care hospital. }\end{array}$ & $\begin{array}{l}\text { Investigators' roles } \\
\text { defined. Two } \\
\text { person consensus } \\
\text { used for analysis. } \\
\text { Employed a } \\
\text { process of } \\
\text { debriefing among } \\
\text { researchers, } \\
\text { engagement with } \\
\text { the raw data and } \\
\text { codes, and field } \\
\text { data and reflective } \\
\text { notes used to } \\
\text { improve reliability } \\
\text { and validity. }\end{array}$ & $\begin{array}{l}\text { Patients } \\
\text { referred by } \\
\text { the nurse } \\
\text { caring for the } \\
\text { patient with } \\
\text { patient's } \\
\text { permission. } \\
\text { Eligibility } \\
\text { included a fall } \\
\text { within } 48 \\
\text { hours, } \\
\text { cognitively } \\
\text { intact, ability } \\
\text { to } \\
\text { communicate, } \\
\text { and English } \\
\text { speaking. } 2 \\
\text { men and } 7 \\
\text { women, age } \\
\text { range } 24-78, \\
\text { mean age }\end{array}$ & $\begin{array}{l}\text { Verbatim interviews } \\
\text { converted to NVivo } \\
\text { software for coding } \\
\text { and analysis. Two } \\
\text { categories were } \\
\text { identified to explain } \\
\text { why these patients } \\
\text { fell. Patients } \\
\text { identified strategies } \\
\text { they believed would } \\
\text { help to prevent falls. }\end{array}$ & $\begin{array}{l}\text { The need to toilet coupled with } \\
\text { a loss of balance and weakness } \\
\text { that was unexpected was } \\
\text { identified as two categories } \\
\text { explained by the participants. } \\
\text { The loss of balance when } \\
\text { experiencing an urgent need to } \\
\text { toilet was the most reported } \\
\text { reason for falling. Patients } \\
\text { reported activities to reduce } \\
\text { falls as: being involved in } \\
\text { assessing their own limits, } \\
\text { understanding their fall risk } \\
\text { assessment, overcoming the } \\
\text { emotional obstacle of not } \\
\text { wanting to bother the nurse, } \\
\text { and having proper ambulation } \\
\text { devices available. The major } \\
\text { implication is the patient's } \\
\text { need to feel that they can ask } \\
\text { for assistance before }\end{array}$ \\
\hline
\end{tabular}




\begin{tabular}{|c|c|c|c|c|c|c|}
\hline & & & & $\begin{array}{l}61.2 \\
\mathrm{~N}=9\end{array}$ & & ambulating. \\
\hline $\begin{array}{l}\text { Dykes et al. } \\
\text { (2009) }\end{array}$ & $\begin{array}{l}\text { To determine the } \\
\text { views of } \\
\text { registered nurses } \\
\text { (RN's) and } \\
\text { nursing } \\
\text { assistants (NA's) } \\
\text { as to why } \\
\text { patients in acute } \\
\text { care fall and how } \\
\text { falls could be } \\
\text { prevented. }\end{array}$ & $\begin{array}{l}\text { Qualitative } \\
\text { descriptive study } \\
\text { design using } \\
\text { audiotaped focus } \\
\text { groups (4 RN and } \\
4 \text { NA groups) from } \\
\text { four acute } \\
\text { hospitals, two } \\
\text { urban academic } \\
\text { and two suburban } \\
\text { teaching from the } \\
\text { same hospital } \\
\text { system }\end{array}$ & $\begin{array}{l}\text { Methodology of } \\
\text { the moderator led } \\
\text { focus groups was } \\
\text { provided. Raw } \\
\text { data was coded } \\
\text { using a two person } \\
\text { consensus } \\
\text { approach. Basic } \\
\text { content analysis } \\
\text { methods were used } \\
\text { to interpret the } \\
\text { data. Researchers } \\
\text { were engaged } \\
\text { through debriefing, } \\
\text { engagement with } \\
\text { the raw data and } \\
\text { coding, and use of } \\
\text { field notes. Small } \\
\text { sample size } \\
\text { however use of } \\
\text { four hospital sites } \\
\text { strengthened }\end{array}$ & $\begin{array}{l}\text { Four focus } \\
\text { group } \\
\text { interviews } \\
\text { with } 3 \text { to } 10 \\
\text { RN's and four } \\
\text { focus groups } \\
\text { with } 4 \text { to } 6 \\
\text { NA's from } \\
\text { four acute } \\
\text { care hospitals. } \\
\text { Participants } \\
\text { recruited by } \\
\text { invitation and } \\
\text { flyers. } \\
\text { N=23 RN's } \\
\text { N=19 NA's }\end{array}$ & $\begin{array}{l}\text { Raw data was } \\
\text { reviewed and } \\
\text { corrected, removing } \\
\text { identifying } \\
\text { characteristics. Data } \\
\text { was converted to } \\
\text { NVivo software and } \\
\text { open coded. } \\
\text { Concepts were then } \\
\text { linked. }\end{array}$ & $\begin{array}{l}\text { Six concepts were developed } \\
\text { to prevent patient falls } \\
\text { including patient report, } \\
\text { information access, signage, } \\
\text { environment, teamwork and } \\
\text { involving the patient and } \\
\text { family. Facilitators and } \\
\text { barriers were identified related } \\
\text { to these concepts. A predictive } \\
\text { conceptual model is presented } \\
\text { on the likelihood of patients } \\
\text { falling based on the data. } \\
\text { Organizations must strengthen } \\
\text { facilitators within two common } \\
\text { categories; } \\
\text { Knowledge/Communication } \\
\text { and Capability/Actions, i.e., } \\
\text { facilitated timely report, access } \\
\text { to individual risk information } \\
\text { for caregivers and } \\
\text { patient/family and overcome } \\
\text { barriers i.e., patients not }\end{array}$ \\
\hline
\end{tabular}




\begin{tabular}{|c|c|c|c|c|c|c|}
\hline & & & generalizability. & & & $\begin{array}{l}\text { following instructions, } \\
\text { teamwork, access to } \\
\text { equipment. }\end{array}$ \\
\hline $\begin{array}{l}\text { Hitcho et al. } \\
(2004)\end{array}$ & $\begin{array}{l}\text { To identify and } \\
\text { analyze } \\
\text { characteristics, } \\
\text { circumstances, } \\
\text { factors } \\
\text { contributing to } \\
\text { patient falls, fall } \\
\text { rates by service } \\
\text { area and staffing } \\
\text { patterns. To } \\
\text { measure the } \\
\text { extent of serious } \\
\text { injury resulting } \\
\text { from inpatient } \\
\text { falls and analyze } \\
\text { risk factors for } \\
\text { injury among } \\
\text { those who fall. }\end{array}$ & $\begin{array}{l}\text { Prospective } \\
\text { Descriptive Study } \\
\text { Falls in one } \\
\text { academic medical } \\
\text { center. Data from } \\
\text { incident reports, } \\
\text { patient medical } \\
\text { records, and } \\
\text { interviews with } \\
\text { nurses and } \\
\text { patients. }\end{array}$ & $\begin{array}{l}\text { Some potential for } \\
\text { bias existed. } \\
\text { Method for } \\
\text { assuring reliability } \\
\text { between two } \\
\text { researchers was } \\
\text { not provided. Data } \\
\text { from one academic } \\
\text { medical center. }\end{array}$ & $\begin{array}{l}\text { Sample } \\
\text { included falls } \\
\text { from a1300 } \\
\text { bed academic } \\
\text { medical } \\
\text { center as } \\
\text { reported in an } \\
\text { electronic } \\
\text { incident } \\
\text { system over a } \\
3 \text { month } \\
\text { period. } \\
\text { Behavioral } \\
\text { health and } \\
\text { falls during } \\
\text { physical } \\
\text { therapy } \\
\text { sessions } \\
\text { excluded. } \\
\text { Only first falls } \\
\text { by patients } \\
\text { were }\end{array}$ & $\begin{array}{l}\text { Parametric and } \\
\text { nonparametric } \\
\text { analysis of data } \\
\text { using SPSS for } \\
\text { Windows. Data } \\
\text { were double entered } \\
\text { for accuracy. }\end{array}$ & $\begin{array}{l}\text { Mean age of fallers } 63.4 \text { (range } \\
\text { 17-96) however half (50\%) of } \\
\text { falls were due to elimination } \\
\text { and more common in age } 65 \\
\text { and older ( } 83 \% \text { vs. } 48 \% \text {; } \\
\mathrm{P}=.001 \text { ). } 85 \% \text { of falls occurred } \\
\text { in the patient's room and 59\% } \\
\text { during the evening and night } \\
\text { time. } 29 \% \text { of fallers reported } \\
\text { using an assistive device at } \\
\text { home but only } 6 \% \text { were using } \\
\text { one when they fell in the } \\
\text { hospital. } 42 \% \text { of falls resulted } \\
\text { in some type of injury with } \\
\text { elimination correlating with } \\
\text { fall injuries (cOR, } 2.5 ; 95 \% \\
\text { CI, } 1.2 \text { to 5.2). } 8 \% \text { of falls } \\
\text { involved moderate to severe } \\
\text { injury. Of patients who fell } \\
81 \% \text { were with general muscle } \\
\text { weakness and } 36 \% \text { with } \\
\text { urinary frequency. Of }\end{array}$ \\
\hline
\end{tabular}




\begin{tabular}{|c|c|c|c|c|c|c|}
\hline & & & & $\begin{array}{l}\text { included. } \\
\mathrm{N}=183\end{array}$ & & $\begin{array}{l}\text { medications administered } \\
\text { within past } 24 \text { hours of falling, } \\
\text { central nervous system drugs } \\
\text { were administered to } 58 \% \text { of } \\
\text { fallers and } 56 \% \text { received } \\
\text { vasoactive/blood pressure } \\
\text { agents. Implications for } \\
\text { provision of assistive devices } \\
\text { and routine elimination } \\
\text { schedules. Many patients need } \\
\text { education related to the effects } \\
\text { of hospitalization i.e., new } \\
\text { environment, medications, } \\
\text { decreased activity, tests, and } \\
\text { treatments may have and these } \\
\text { factors require use of call bell } \\
\text { for assistance. }\end{array}$ \\
\hline Tzeng (2010) & $\begin{array}{l}\text { Determine the } \\
\text { prevalence of } \\
\text { falls that are } \\
\text { associated with } \\
\text { toileting in the } \\
\text { acute inpatient } \\
\text { setting. }\end{array}$ & $\begin{array}{l}\text { Qualitative } \\
\text { retrospective study } \\
\text { design of four } \\
\text { adult inpatient } \\
\text { acute units, in one } \\
\text { suburban } \\
\text { Michigan hospital } \\
\text { using content }\end{array}$ & $\begin{array}{l}\text { Researcher alone } \\
\text { completed the } \\
\text { content analysis } \\
\text { which could result } \\
\text { in bias. Clear } \\
\text { account of } \\
\text { methods provided. } \\
\text { SPSS software for }\end{array}$ & $\begin{array}{l}\text { Electronic } \\
\text { incident } \\
\text { reports of } \\
\text { slip/falls } \\
\text { defined as a } \\
\text { patient found } \\
\text { on the floor or } \\
\text { lowered to the }\end{array}$ & $\begin{array}{l}\text { Content analysis was } \\
\text { used to code the } \\
\text { nurse's narrative } \\
\text { description of falls. } \\
\text { The theme of each } \\
\text { fall was coded to a } \\
\text { single-choice } \\
\text { variable and }\end{array}$ & $\begin{array}{l}\text { Findings showed that } 45.2 \% \text { of } \\
\text { the falls were toileting related. } \\
\text { Of all falls, } 78.2 \% \text { were } \\
\text { patients } 65 \text { and older with } \\
\text { mean age } 75.59 . \text { The most } \\
\text { common toileting-related } \\
\text { theme was when the patient } \\
\text { was on the way from the bed }\end{array}$ \\
\hline
\end{tabular}




\begin{tabular}{|c|c|c|c|c|c|c|}
\hline & & $\begin{array}{l}\text { analysis of the } \\
\text { nurse incident } \\
\text { reports on slip/falls } \\
\text { over a three year } \\
\text { period. }\end{array}$ & $\begin{array}{l}\text { descriptive data } \\
\text { analysis used. }\end{array}$ & $\begin{array}{l}\text { floor. } \\
\mathrm{N}=547\end{array}$ & $\begin{array}{l}\text { descriptive analysis } \\
\text { findings were } \\
\text { generated on the } \\
\text { identified themes } \\
\text { using SPSS } \\
\text { software. }\end{array}$ & $\begin{array}{l}\text { or chair to the bathroom or } \\
\text { from the bathroom back to the } \\
\text { bed or the chair. Strategies are } \\
\text { needed to address patients' } \\
\text { toileting needs to prevent falls. }\end{array}$ \\
\hline $\begin{array}{l}\text { Tzeng \& Yin } \\
\text { (2009) }\end{array}$ & $\begin{array}{l}\text { To understand } \\
\text { the opinions and } \\
\text { observations of } \\
\text { recently } \\
\text { discharged } \\
\text { senior patients } \\
\text { about the fall- } \\
\text { prevention } \\
\text { program } \\
\text { received during } \\
\text { their most recent } \\
\text { hospitalization, } \\
\text { with a focus on } \\
\text { the extrinsic risk } \\
\text { factors for falls. }\end{array}$ & $\begin{array}{l}\text { Qualitative cross- } \\
\text { sectional } \\
\text { exploratory study } \\
\text { Three nurses and } \\
\text { two occupational } \\
\text { therapists collected } \\
\text { data from home } \\
\text { care patients } \\
\text { discharged within } \\
30 \text { days from a } \\
\text { hospital. Data was } \\
\text { collected using a } \\
\text { two sided, } 1 \text { page } \\
\text { survey tool. Items } \\
\text { were either single- } \\
\text { item scales or open } \\
\text { ended questions. } \\
\text { Part of the survey }\end{array}$ & $\begin{array}{l}\text { Survey tool was } \\
\text { piloted. Data } \\
\text { collectors received } \\
\text { training and } \\
\text { demonstrated } \\
\text { understanding of } \\
\text { the tool to assure } \\
\text { interrater } \\
\text { reliability. The } \\
\text { survey questions } \\
\text { were provided. } \\
\text { Researchers } \\
\text { followed up with } \\
\text { data collectors } 2 \\
\text { weeks into the } \\
\text { study and were } \\
\text { available for } \\
\text { questions. }\end{array}$ & $\begin{array}{l}\text { Medicare } \\
\text { patients open } \\
\text { to home care } \\
\text { during an } 8 \\
\text { month period, } \\
\text { at least } 65 \\
\text { years old, } \\
\text { alert, and } \\
\text { could } \\
\text { independently } \\
\text { communicate. } \\
50.5 \% \text { were } \\
\text { men and mean } \\
\text { age was } \\
76.97 \text {. } \\
\text { N=91 }\end{array}$ & $\begin{array}{l}\text { SPSS software was } \\
\text { used to enter data, } \\
\text { manage, and analyze } \\
\text { the quantitative and } \\
\text { content data. Open } \\
\text { ended questions } \\
\text { were categorized } \\
\text { into themes using } \\
\text { the authors own } \\
\text { typology for the } \\
\text { extrinsic factors. } \\
\text { Descriptive, } \\
\text { correlation analyses } \\
\text { and chi-square tests } \\
\text { were employed to } \\
\text { examine the data. }\end{array}$ & $\begin{array}{l}57.1 \% \text { of participants did not } \\
\text { believe the fall-prevention } \\
\text { program during their previous } \\
\text { hospitalization was adequate. } \\
\text { Bed height to high, insufficient } \\
\text { fall-prevention education, lack } \\
\text { of ambulation devices, provide } \\
\text { more physical therapy, and } \\
\text { clear pathways in the rooms } \\
\text { with pull bars were } \\
\text { suggestions made by } \\
\text { participants. Feedback also } \\
\text { included the need for nurses to } \\
\text { repeat messages on falls } \\
\text { frequently, monitor patients } \\
\text { often, and answer call bells } \\
\text { timely. In addition to } \\
\text { environmental implications, }\end{array}$ \\
\hline
\end{tabular}




\begin{tabular}{|c|c|c|c|c|c|c|}
\hline & & $\begin{array}{l}\text { was completed } \\
\text { prior to the } \\
\text { interview by } \\
\text { looking at the } \\
\text { patient's OASIS } \\
\text { assessment data }\end{array}$ & $\begin{array}{l}\text { Quantitative and } \\
\text { content analyses } \\
\text { were performed. } \\
\text { Content analysis } \\
\text { was conducted } \\
\text { independently by } \\
\text { each researcher } \\
\text { after which a } \\
\text { consensus was } \\
\text { reached to ensure } \\
\text { accuracy. }\end{array}$ & & & $\begin{array}{l}\text { there is need to include a well } \\
\text { designed patient education } \\
\text { program with methods that } \\
\text { engage the patient. Nurses } \\
\text { need to incorporate visual cues } \\
\text { as part of the patient's } \\
\text { education. Increasing the } \\
\text { repetition of fall prevention } \\
\text { messages to patients is } \\
\text { necessary. }\end{array}$ \\
\hline $\begin{array}{l}\text { Yardley et al. } \\
(2006)\end{array}$ & $\begin{array}{l}\text { To gain an un- } \\
\text { derstanding of } \\
\text { older people's } \\
\text { perceptions of } \\
\text { falls prevention } \\
\text { advice, and how } \\
\text { best to design } \\
\text { communications } \\
\text { that will } \\
\text { encourage older } \\
\text { people to take } \\
\text { action to prevent } \\
\text { falls. }\end{array}$ & $\begin{array}{l}\text { Qualitative } \\
\text { descriptive study } \\
\text { design } \\
\text { Focus group } \\
\text { interviews and one } \\
\text { to one interviews } \\
\text { for disabled } \\
\text { homebound } \\
\text { participants were } \\
\text { deployed. } \\
\text { Explored previous } \\
\text { experience of } \\
\text { messages }\end{array}$ & $\begin{array}{l}\text { Small group } \\
\text { formats, } \\
\text { methodology } \\
\text { explained. } \\
\text { Interviews were } \\
\text { audiotaped and } \\
\text { fully transcribed. } \\
\text { One researcher led } \\
\text { the group and } \\
\text { individual } \\
\text { interviews and } \\
\text { another recorded } \\
\text { the speakers for }\end{array}$ & $\begin{array}{l}\text { United } \\
\text { Kingdom } \\
\text { community } \\
\text { dwelling older } \\
\text { adults age } 61 \\
\text { to } 94 \\
\text { recruited. } 18 \\
\text { men and } 48 \\
\text { women } \\
\text { participated. } \\
\text { Recruitment } \\
\text { messages } \\
\text { were changed } \\
\text { to recruit }\end{array}$ & $\begin{array}{l}\text { Researchers all were } \\
\text { involved in review } \\
\text { of the transcripts. } \\
\text { Themes were } \\
\text { developed and } \\
\text { constant comparison } \\
\text { technique was used } \\
\text { to examine the } \\
\text { context of opinions. } \\
\text { Critical review by all } \\
\text { researchers was final } \\
\text { step. }\end{array}$ & $\begin{array}{l}\text { While there was general } \\
\text { endorsement for the value of } \\
\text { falls prevention education } \\
\text { these older adults stated they } \\
\text { may not use all the advice. } \\
\text { Some agreed that it was useful } \\
\text { but not for them, only the } \\
\text { disabled elderly. Perceptions } \\
\text { of negativity to the messages } \\
\text { related to it being authoritarian } \\
\text { and patronizing, belief that } \\
\text { falls are inevitable, and the } \\
\text { messages make the older } \\
\text { person anxious and depressed. }\end{array}$ \\
\hline
\end{tabular}




\begin{tabular}{|c|c|c|c|c|c|c|}
\hline & & $\begin{array}{l}\text { regarding falling. } \\
\text { Examples of health } \\
\text { promotion } \\
\text { messages about } \\
\text { falling prevention } \\
\text { were presented. }\end{array}$ & accuracy. & $\begin{array}{l}\text { healthy, less } \\
\text { frail } \\
\text { participants. } \\
\mathrm{N}=66\end{array}$ & & $\begin{array}{l}\text { Recommendation from } \\
\text { participants was to promote } \\
\text { exercise, incorporate the } \\
\text { messages into general health } \\
\text { promotion activities, provide } \\
\text { messages as positive } \\
\text { suggestions and give } \\
\text { explanations and rationale. } \\
\text { These findings imply that older } \\
\text { people will deny their risk of } \\
\text { falling to maintain dignity. } \\
\text { For community dwellers, } \\
\text { concentrating on positive } \\
\text { balance improvement mobility } \\
\text { rather than hazard messages. } \\
\text { However, there also may need } \\
\text { to be increased efforts on } \\
\text { messages related to actual } \\
\text { vulnerability for older adults to } \\
\text { reduce the stigma. }\end{array}$ \\
\hline $\begin{array}{l}\text { VonDras \& } \\
\text { Madey (2004) }\end{array}$ & $\begin{array}{l}\text { To explore the } \\
\text { theory of } \\
\text { planned behavior } \\
\text { (TPB) and social } \\
\text { support }\end{array}$ & $\begin{array}{l}\text { Qualitative survey } \\
\text { (postal and } \\
\text { telephone) design } \\
\text { using idiographic }\end{array}$ & $\begin{array}{l}\text { Subjects randomly } \\
\text { approached for } \\
\text { inclusion. No } \\
\text { benefits to } \\
\text { participants. }\end{array}$ & $\begin{array}{l}\text { Sample } \\
\text { obtained from } \\
\text { the Washing- } \\
\text { ton University } \\
\text { Aging and }\end{array}$ & $\begin{array}{l}\text { Age effects, } \\
\text { demographic } \\
\text { characteristics and } \\
\text { study variables } \\
\text { analyzed using Chi- }\end{array}$ & $\begin{array}{l}\text { The predictive relationships of } \\
\text { all aspects of TPB were } \\
\text { observed in the study. Results } \\
\text { suggest a high association } \\
\text { between behavioral intent and }\end{array}$ \\
\hline
\end{tabular}




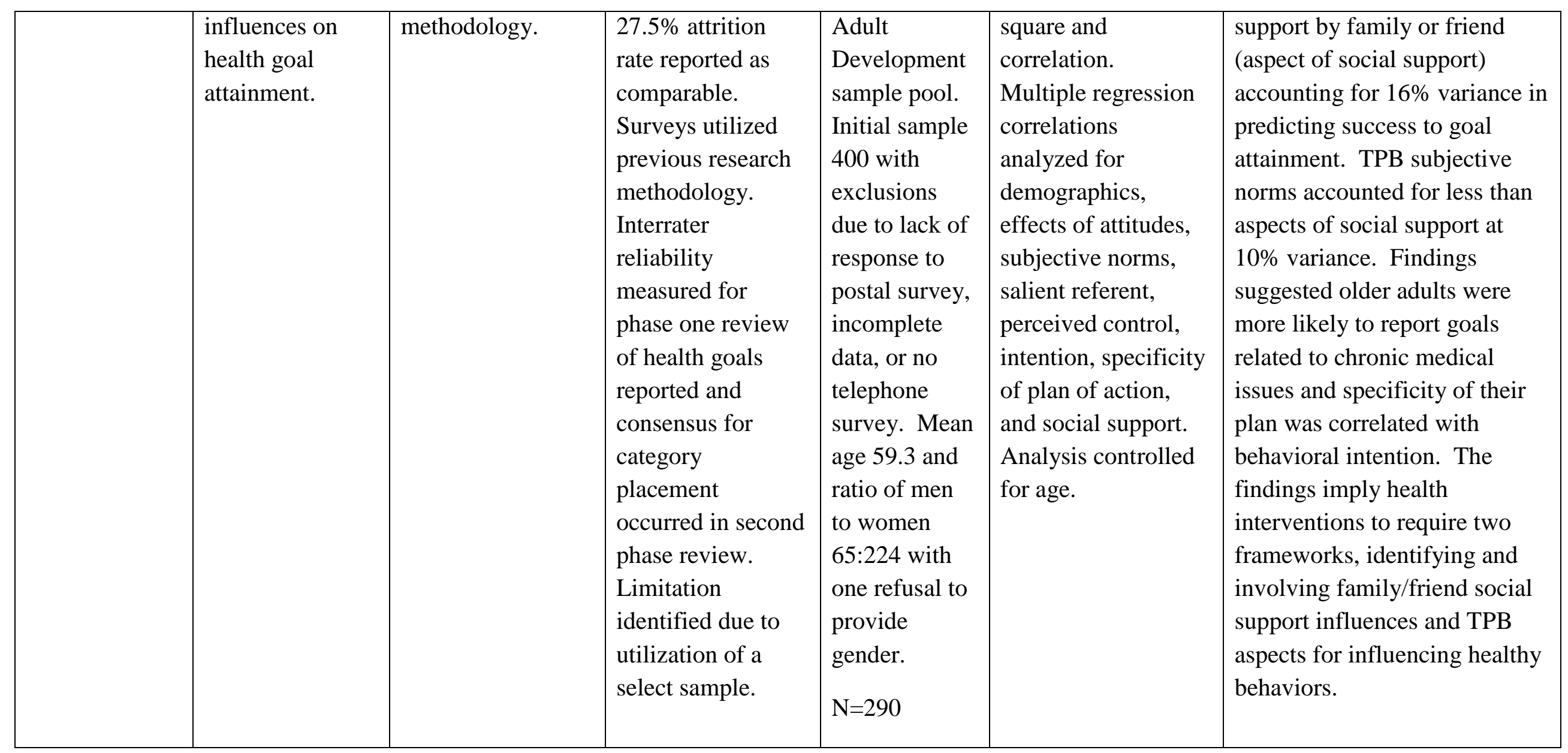


Table 2: Description of Quantitative Studies

\begin{tabular}{|c|c|c|c|c|c|c|c|}
\hline Author & $\begin{array}{l}\text { Purpose of } \\
\text { Study }\end{array}$ & $\begin{array}{l}\text { Study } \\
\text { Design: } \\
\text { Type of } \\
\text { Design }\end{array}$ & $\begin{array}{l}\text { Hypothesis; } \\
\text { Reliability }\end{array}$ & $\begin{array}{l}\text { Variables: } \\
\text { Dependent and } \\
\text { Independent; } \\
\text { Measurement } \\
\text { (how variables are } \\
\text { defined) }\end{array}$ & $\begin{array}{l}\text { Sample } \\
\text { description } \\
\text { and } \\
\text { Number }\end{array}$ & $\begin{array}{l}\text { Type of } \\
\text { Analysis }\end{array}$ & $\begin{array}{l}\text { Major findings and } \\
\text { implication }\end{array}$ \\
\hline $\begin{array}{l}\text { Bates et al. } \\
(1995)\end{array}$ & $\begin{array}{l}\text { 1) Evaluate the } \\
\text { correlates } \\
\text { associated with } \\
\text { serious falls in } \\
\text { hospitalized } \\
\text { patients } \\
\text { 2) Evaluate the } \\
\text { association } \\
\text { between serious } \\
\text { falls and } \\
\text { medications } \\
\text { 2) Determine an } \\
\text { estimated total } \\
\text { charges and } \\
\text { additional length }\end{array}$ & $\begin{array}{l}\text { Retrospective } \\
\text { case-control } \\
\text { study. }\end{array}$ & $\begin{array}{l}\text { No statement of } \\
\text { hypothesis } \\
\text { given. Single } \\
\text { hospital site } \\
\text { increased } \\
\text { reliability. } \\
\text { Nurse } \\
\text { abstracting } \\
\text { blinded to case } \\
\text { status. 10\% } \\
\text { sample of charts } \\
\text { reviewed second } \\
\text { time for } \\
\text { reliability. } \\
\text { Power analysis } \\
\text { completed. IRB }\end{array}$ & $\begin{array}{l}\text { Dependent } \\
\text { variable- Presence } \\
\text { of fall with injury. } \\
\text { Independent } \\
\text { variables- } 37 \\
\text { variables including } \\
\text { data on demo- } \\
\text { graphics, admission } \\
\text { physical exams, } \\
\text { and variables } \\
\text { present the day } \\
\text { before fall. The } \\
\text { Charlson co- } \\
\text { morbidity score } \\
\text { was utilized to } \\
\text { calculate a score for }\end{array}$ & $\begin{array}{l}\text { Case } \\
\text { controls } \\
\text { chosen } \\
\text { randomly } \\
\text { matching to } \\
\text { serious falls } \\
\text { cases by } \\
\text { three month } \\
\text { period dates } \\
\text { of hospital- } \\
\text { ization, } \\
\text { gender, age, } \\
\text { and length of } \\
\text { stay before } \\
\text { the fall. } \\
\mathrm{N}=62 \text { Case }\end{array}$ & $\begin{array}{l}\text { Univariate } \\
\text { and } \\
\text { multivar- } \\
\text { iate } \\
\text { analysis } \\
\text { were used } \\
\text { to } \\
\text { determine } \\
\text { correlation } \\
\text { between } \\
\text { the } 37 \\
\text { indepen- } \\
\text { dent } \\
\text { variables. }\end{array}$ & $\begin{array}{l}\text { Using univariate analysis } \\
\text { only the CAM score } \\
(\mathrm{p}=.005) \text { and the } \\
\text { Comorbidity score ( } \mathrm{p}=.001 \text { ) } \\
\text { were significant correlates of } \\
\text { falls. Medications were not } \\
\text { statistically significant } \\
\text { correlates of falls and the } \\
\text { mean number of drugs within } \\
24 \text { hours }(6.4+/-3.4 \text { vs. } 6.1 \\
+/-3.7) \text { and number of drugs } \\
\text { within } 4 \text { days ( } 8.7+/-4.4 \text { vs. } \\
8.5+/-5.3) \text { were similar in } \\
\text { cases and controls. In the } \\
\text { multivariate analysis only the } \\
\text { Charlson comorbidity index } \\
\text { (OR } 1.4 ; 95 \% \text { CI } 1.1 \text { to } 1.7)\end{array}$ \\
\hline
\end{tabular}




\begin{tabular}{|c|c|c|c|c|c|c|c|}
\hline & $\begin{array}{l}\text { of stay } \\
\text { associated with } \\
\text { a serious fall }\end{array}$ & & approved. & $\begin{array}{l}\text { comorbid } \\
\text { conditions and the } \\
\text { Confusion } \\
\text { Assessment } \\
\text { Method (CAM) } \\
\text { instrument to } \\
\text { determine } \\
\text { presences of } \\
\text { delirium. } \\
\text { Utilization data } \\
\text { included length of } \\
\text { hospital stay, time } \\
\text { in CCU, and } \\
\text { charges. }\end{array}$ & $\begin{array}{l}\text { Control } \\
\text { Pairs }\end{array}$ & & $\begin{array}{l}\text { and the CAM score (OR 1.6; } \\
95 \% \text { CI } 1.1 \text { to } 2.5 \text { were } \\
\text { independent correlates of a } \\
\text { fall. Falls correlated with an } \\
\text { increase length of stay } \\
(\mathrm{p}<0.004) \text { of } 12 \text { days longer } \\
\text { and increased total charges } \\
\text { ( }<<0.008) \text { of } \$ 4,233 \\
\text { compared with controls. } \\
\text { Multivariate analysis of } \\
\text { resource utilization } \\
\text { correlated with a } 71 \% \\
\text { increase in length of stay and } \\
61 \% \text { higher total charges. } \\
\text { The findings suggest } \\
\text { confusion and comorbidities } \\
\text { increase the risk of fall } \\
\text { injuries and resource } \\
\text { utilization is increased. }\end{array}$ \\
\hline $\begin{array}{l}\text { Dykes et al. } \\
(2010)\end{array}$ & $\begin{array}{l}\text { To determine } \\
\text { whether a fall } \\
\text { prevention tool } \\
\text { kit using health } \\
\text { information } \\
\text { technology (IT) }\end{array}$ & $\begin{array}{l}\text { Cluster } \\
\text { randomized } \\
\text { study design }\end{array}$ & $\begin{array}{l}\text { No stated } \\
\text { hypothesis. A } \\
\text { power analysis } \\
\text { was conducted } \\
\text { for a target } \\
\text { sample of } 5100\end{array}$ & $\begin{array}{l}\text { Primary Dependent } \\
\text { Variable- patient } \\
\text { falls per } 1000 \\
\text { patient-days in } \\
\text { targeted unit during } \\
\text { study period. }\end{array}$ & $\begin{array}{l}\text { All patients } \\
\text { admitted to } \\
\text { all study } \\
\text { units during } \\
\text { a } 6 \text { month } \\
\text { study period. }\end{array}$ & $\begin{array}{l}\text { Parametric } \\
\text { analysis } \\
\text { across } \\
\text { treatment } \\
\text { groups } \\
\text { used. A }\end{array}$ & $\begin{array}{l}\text { Tool kit outputs were printed } \\
\text { for } 93.2 \% \text { of patients. } \\
\text { Adherence in placing bed } \\
\text { posters above the patient bed } \\
\text { was } 89 \% \text {. Intervention units } \\
\text { had a significantly lower fall }\end{array}$ \\
\hline
\end{tabular}




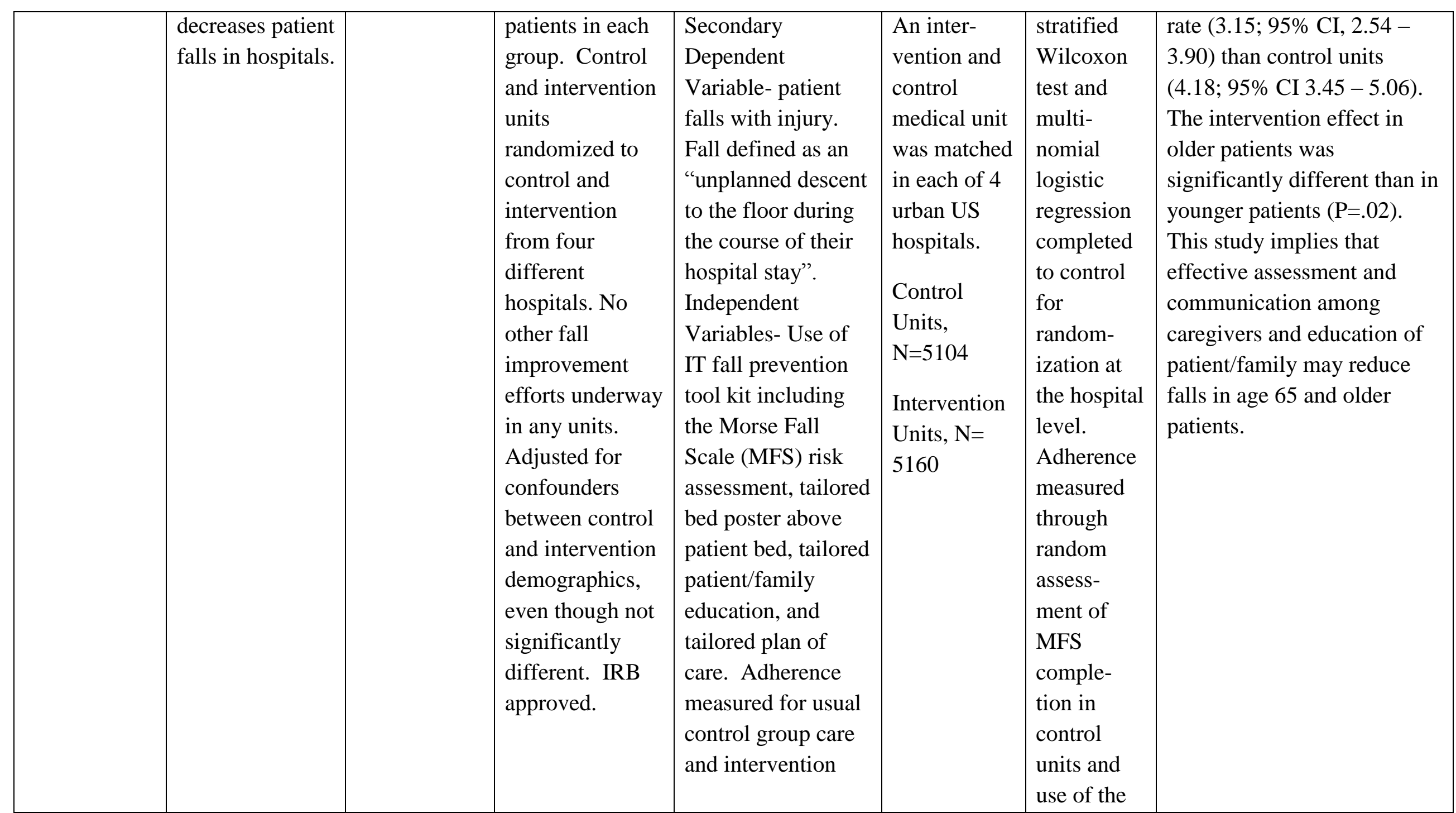




\begin{tabular}{|c|c|c|c|c|c|c|c|}
\hline & & & & group care. & & $\begin{array}{l}\text { tool kit in } \\
\text { interven- } \\
\text { tion units. }\end{array}$ & \\
\hline $\begin{array}{l}\text { Haines et al. } \\
(2011)\end{array}$ & $\begin{array}{l}\text { To determine if } \\
\text { a patient } \\
\text { education } \\
\text { intervention is } \\
\text { effective in } \\
\text { isolation and } \\
\text { equally effective } \\
\text { for patients who } \\
\text { have intact vs. } \\
\text { those with } \\
\text { impaired } \\
\text { cognitive } \\
\text { function. }\end{array}$ & $\begin{array}{l}\text { Three group } \\
\text { RCT } \\
\text { Two } \\
\text { intervention } \\
\text { groups } \\
\text { receiving } \\
\text { differing } \\
\text { models of } \\
\text { patient fall } \\
\text { education } \\
\text { and the third } \\
\text { group } \\
\text { receiving } \\
\text { only usual } \\
\text { care with no } \\
\text { specific falls } \\
\text { education } \\
\text { model. }\end{array}$ & $\begin{array}{l}\text { No stated } \\
\text { hypothesis. } \\
\text { Blinding to } \\
\text { recruiters, data } \\
\text { collectors, and } \\
\text { statistical } \\
\text { analysts. } \\
\text { Randomization } \\
\text { by computerized } \\
\text { allocation } \\
\text { sequence with } \\
\text { masking } \\
\text { protected. } \\
\text { Power analysis } \\
\text { was conducted. } \\
\text { IRB approved. }\end{array}$ & $\begin{array}{l}\text { Dependent } \\
\text { Variable- patient } \\
\text { falls, defined using } \\
\text { the World Health } \\
\text { Organization } \\
\text { definition, "an } \\
\text { event which results } \\
\text { in a person coming } \\
\text { to rest inadvertently } \\
\text { on the ground or } \\
\text { floor or other lower } \\
\text { level." Independent } \\
\text { variables- 1) } \\
\text { written and video } \\
\text { education materials } \\
\text { and } 1 \text { to } 1 \text { follow- } \\
\text { up with a health } \\
\text { professional with } \\
\text { content and pro- } \\
\text { gression based on } \\
\text { the health belief } \\
\text { model 2) Written }\end{array}$ & $\begin{array}{l}\text { Patients } \\
\text { admitted to a } \\
\text { mixture of } \\
\text { acute care } \\
\text { units and } \\
\text { subacute } \\
\text { care units in } \\
\text { two } \\
\text { Australian } \\
\text { hospitals } \\
\text { over } 16 \\
\text { months. } \\
\text { Complete } \\
\text { Program } \\
\text { Intervention } \\
\text { Group 1, } \\
\text { N=401 } \\
\text { Materials } \\
\text { only } \\
\text { Intervention }\end{array}$ & $\begin{array}{l}\text { Analyses } \\
\text { adjusted } \\
\text { for whether } \\
\text { patient } \\
\text { treated on } \\
\text { subacute or } \\
\text { acute unit. } \\
\text { Logistic } \\
\text { regression } \\
\text { used to } \\
\text { compare } \\
\text { patients } \\
\text { with } 1 \text { or } \\
\text { more falls } \\
\text { between } \\
\text { groups }\end{array}$ & $\begin{array}{l}\text { Rate of falls was } \\
\text { significantly lower among } \\
\text { patients with intact cognition } \\
\text { and allocated to the complete } \\
\text { program group ( } 4.01 \text { falls per } \\
\text { per } 1000 \text { patient days) } \\
\text { compared with the rate of } \\
\text { participants allocated to the } \\
\text { control ( } 8.72 \text { falls per } 1000 \\
\text { patient days) and materials- } \\
\text { only group ( } 8.18 \text { falls per } \\
1000 \text { patient days). Patients } \\
\text { with cognitive impairment } \\
\text { who received the complete } \\
\text { program fell at a } \\
\text { significantly higher rate than } \\
\text { those in the control group } \\
\text { ( } 7.49 \text { vs. } 2.89 \text { ). There is } \\
\text { some evidence that the, } \\
\text { complete education program } \\
\text { using } 1 \text { to } 1 \text { follow-up may } \\
\text { reduce falls in cognitively }\end{array}$ \\
\hline
\end{tabular}




\begin{tabular}{|c|c|c|c|c|c|c|c|}
\hline & & & & $\begin{array}{l}\text { and video-based } \\
\text { materials without } \\
\text { the } 1 \text { to } 1 \text { follow-up } \\
\text { with content and } \\
\text { progression based } \\
\text { on the health belief } \\
\text { model. }\end{array}$ & $\begin{array}{l}\text { Group, } \\
\mathrm{N}=424 \\
\text { Control } \\
\text { Group, } \\
\mathrm{N}=381\end{array}$ & & $\begin{array}{l}\text { intact patients. However, the } \\
\text { program is time intensive ( } 20 \\
\text { to } 36 \text { minutes per patient). }\end{array}$ \\
\hline $\begin{array}{l}\text { Hill et al. } \\
(2009)\end{array}$ & $\begin{array}{l}\text { To compare } \\
\text { effectiveness of } \\
\text { DVD education } \\
\text { with written } \\
\text { delivery of falls } \\
\text { prevention } \\
\text { education } \\
\text { material on } \\
\text { patients self- } \\
\text { perceived risk of } \\
\text { falls, perception } \\
\text { of falls } \\
\text { epidemiology, } \\
\text { knowledge of } \\
\text { falls prevention } \\
\text { strategies, and } \\
\text { confidence and } \\
\text { motivation to }\end{array}$ & $\begin{array}{l}\text { Two- Group } \\
\text { RCT with } \\
\text { quasi- } \\
\text { experimental } \\
\text { control } \\
\text { group. Phase } \\
1 \text { and Phase } \\
2 \text { design. } \\
\text { Control } \\
\text { group } \\
\text { analysis in } \\
\text { Phase } 1 \text {, } \\
\text { Study group } \\
\text { analysis in } \\
\text { Phase } 2 . \\
\text { Measurement } \\
\text { involved a }\end{array}$ & $\begin{array}{l}\text { No hypothesis } \\
\text { stated. Patients } \\
\text { randomized to } \\
\text { the two study } \\
\text { groups. Study } \\
\text { sites were two } \\
\text { hospitals in } \\
\text { different cities } \\
\text { of Australia. } \\
\text { Patient } \\
\text { exclusion } \\
\text { criteria clear. } \\
\text { Investigators } \\
\text { administering } \\
\text { surveys were not } \\
\text { blinded to the } \\
\text { type education } \\
\text { patient received. }\end{array}$ & $\begin{array}{l}\text { Dependent } \\
\text { Variables- Self } \\
\text { perceived risk of } \\
\text { falls, perception of } \\
\text { falls epidemiology, } \\
\text { knowledge of } \\
\text { prevention } \\
\text { strategies, and } \\
\text { motivation and } \\
\text { confidence to } \\
\text { engage in self- } \\
\text { protective } \\
\text { strategies. } \\
\text { Independent } \\
\text { Variables- 1) DVD } \\
\text { education } \\
\text { 2) Workbook }\end{array}$ & $\begin{array}{l}\text { Control } \\
\text { group } \\
\text { patients rec- } \\
\text { ruited in first } \\
\text { year of study } \\
\text { (Phase 1) } \\
\text { and two } \\
\text { study group } \\
\text { patients } \\
\text { recruited } \\
\text { during the } \\
\text { following } \\
\text { year (Phase } \\
\text { 2). } \\
\text { Geriatric, } \\
\text { medical, and } \\
\text { orthopedic } \\
\text { acute wards }\end{array}$ & $\begin{array}{l}\text { Parametric } \\
\text { tests for } \\
\text { group } \\
\text { compare- } \\
\text { isons. } \\
\text { Wilcoxon } \\
\text { rank sum } \\
\text { tests for } \\
\text { comparison } \\
\text { between } \\
\text { groups. } \\
\text { Logistic } \\
\text { regression } \\
\text { analyses to } \\
\text { compare } \\
\text { responses } \\
\text { between } \\
\text { the DVD }\end{array}$ & $\begin{array}{l}\text { There was a within group } \\
\text { increase in self-perceived } \\
\text { risk of falls in the DVD } \\
\text { group after the education ( } \mathrm{P}= \\
\text {.04) while the change within } \\
\text { the workbook group was not } \\
\text { significant ( } \mathrm{P}=.18) \text {. A higher } \\
\text { proportion of participants } \\
\text { who received either from of } \\
\text { education as compared to the } \\
\text { control group, provided } \\
\text { desired responses across all } \\
\text { knowledge items (P<.001). } \\
\text { Participants in the } \mathrm{DVD} \\
\text { study group had higher levels } \\
\text { of confidence ( } \mathrm{P}=.03) \text {, and } \\
\text { motivation ( } \mathrm{P}=.04) \text {, to } \\
\text { engage in self-protective }\end{array}$ \\
\hline
\end{tabular}




\begin{tabular}{|c|c|c|c|c|c|c|c|}
\hline & $\begin{array}{l}\text { engage in self- } \\
\text { protective } \\
\text { strategies. To } \\
\text { determine if } \\
\text { providing either } \\
\text { form of } \\
\text { education versus } \\
\text { no education has } \\
\text { an effect on the } \\
\text { perceptions of } \\
\text { risks of falling } \\
\text { and harm they } \\
\text { face in hospitals. }\end{array}$ & $\begin{array}{l}\text { custom- } \\
\text { designed } \\
\text { survey } \\
\text { addressing } \\
\text { elements of } \\
\text { the Health } \\
\text { Belief } \\
\text { Model. }\end{array}$ & $\begin{array}{l}\text { IRB approval } \\
\text { obtained. }\end{array}$ & education. & $\begin{array}{l}\text { in two } \\
\text { hospitals in } \\
\text { Australia. } \\
\text { Participants } \\
\text { older than } \\
60, \\
\text { cognitively } \\
\text { intact, and } \\
\text { good } \\
\text { eyesight and } \\
\text { hearing. } \\
\text { Control } \\
\text { Group, N= } \\
122 \\
\text { DVD Study } \\
\text { Group, N= } \\
49 \\
\text { Workbook } \\
\text { Study } \\
\text { Group, N= } \\
51\end{array}$ & $\begin{array}{l}\text { group and } \\
\text { the } \\
\text { workbook } \\
\text { group. }\end{array}$ & $\begin{array}{l}\text { strategies than the workbook } \\
\text { study group. There is some } \\
\text { evidence that DVD educa- } \\
\text { tion vs. workbook education } \\
\text { influences patient's } \\
\text { perceptions of fall risk and } \\
\text { motivation to participate in } \\
\text { fall prevention strategies. }\end{array}$ \\
\hline $\begin{array}{l}\text { Krauss et al. } \\
\text { (2007) }\end{array}$ & $\begin{array}{l}\text { To describe } \\
\text { potential }\end{array}$ & $\begin{array}{l}\text { Retrospective } \\
\text { Cohort Study }\end{array}$ & $\begin{array}{l}\text { Reviewed falls } \\
\text { from } 9 \text { hospitals }\end{array}$ & $\begin{array}{l}\text { Dependent } \\
\text { Variable- 1) Mean }\end{array}$ & $\begin{array}{l}\text { Falls from } 9 \\
\text { hospitals }\end{array}$ & $\begin{array}{l}\text { SAS and } \\
\text { SPSS used }\end{array}$ & $\begin{array}{l}\text { For the } 3 \text { year period the fall } \\
\text { rate differed significantly by }\end{array}$ \\
\hline
\end{tabular}




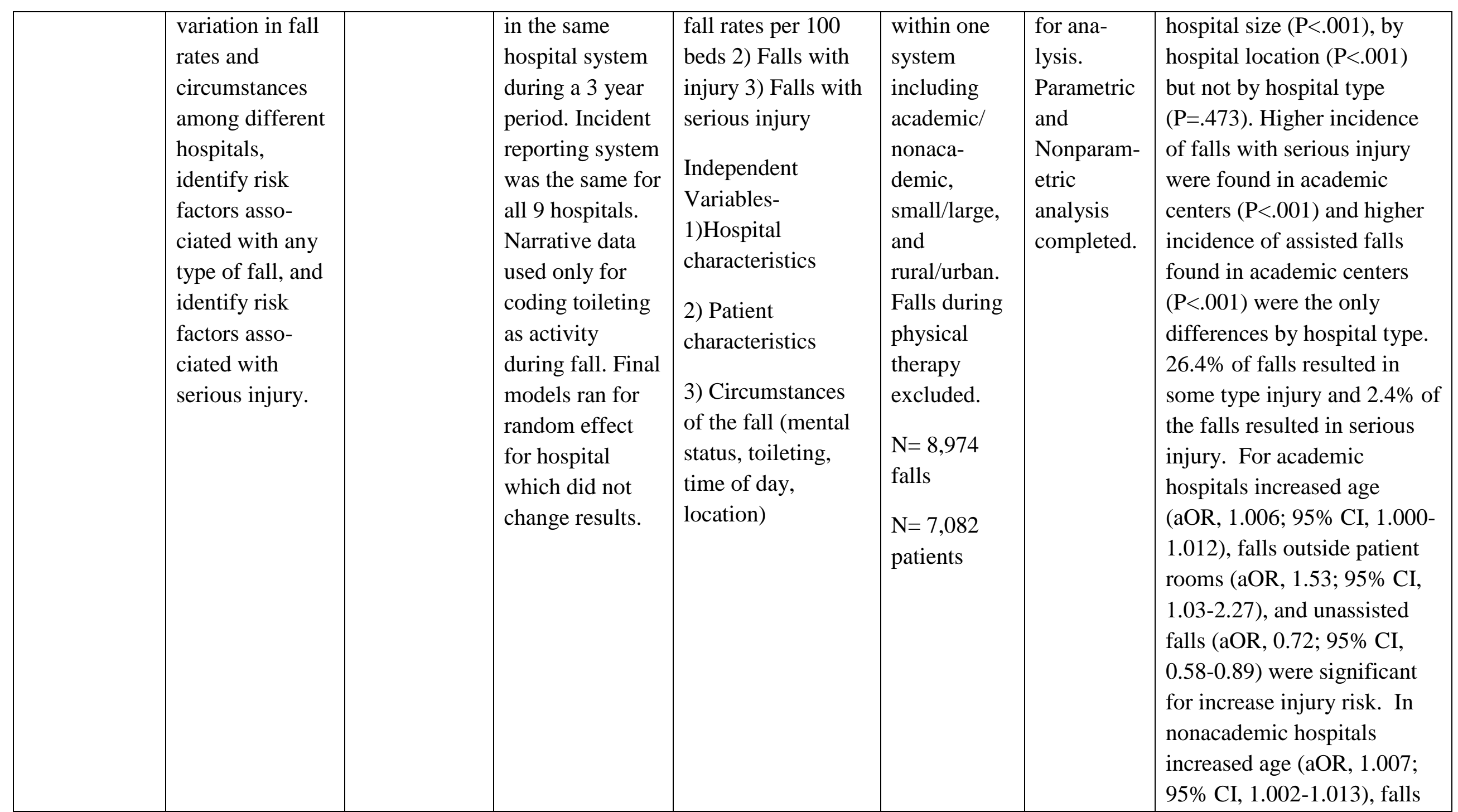




\begin{tabular}{|c|c|c|c|c|c|c|c|}
\hline & & & & & & & $\begin{array}{l}\text { in bathroom (aOR, } 1.46 \text {; } \\
95 \% \mathrm{CI}, 1.06-2.01) \text {, and } \\
\text { unassisted falls (aOR, 1.83; } \\
95 \% \mathrm{CI}, 1.37-2.43 \text { ) were } \\
\text { associated with fall injury. } \\
\text { Female sex (aOR, } 0.83 ; 95 \% \\
\mathrm{CI}, 0.71-0.97 \text { ) was associated } \\
\text { with lower risk of injury. } \\
\text { Older patients must be } \\
\text { targeted for fall prevention } \\
\text { while unassisted and when in } \\
\text { the bathroom. }\end{array}$ \\
\hline $\begin{array}{l}\text { Wong et al. } \\
\text { (2011) }\end{array}$ & $\begin{array}{l}\text { 1) To estimate } \\
\text { the current cost } \\
\text { and length of } \\
\text { stay (LOS) that } \\
\text { can be attributed } \\
\text { to a fall with } \\
\text { serious injury. } \\
\text { 2) Evaluate the } \\
\text { use of optimal } \\
\text { bipartite } \\
\text { matching } \\
(\mathrm{OBM}) \text { analysis }\end{array}$ & $\begin{array}{l}\text { Retrospective } \\
\text { Case-Control } \\
\text { Study }\end{array}$ & $\begin{array}{l}\text { Cases were } \\
\text { randomly } \\
\text { matched to two } \\
\text { controls by } \\
\text { hospital, age } \\
\text { within five } \\
\text { years, year of } \\
\text { discharge, and } \\
\text { diagnosis related } \\
\text { group (DRG). } \\
\text { Three hospitals } \\
\text { were used to }\end{array}$ & $\begin{array}{l}\text { Dependent } \\
\text { Variable- Serious } \\
\text { fall related injury. } \\
\text { Serious injury } \\
\text { defined as defined } \\
\text { as fracture, } \\
\text { subdural hema- } \\
\text { toma, injury } \\
\text { requiring surgical } \\
\text { intervention, or } \\
\text { death. Independent } \\
\text { Variables- Cost and } \\
\text { length of stay }\end{array}$ & $\begin{array}{l}\text { Adult } \\
\text { inpatients } \\
\text { discharged } \\
\text { from one of } \\
3 \text { hospitals, } \\
\text { between } \\
\text { January } \\
2004 \text { and } \\
\text { October } \\
2006, \text { who } \\
\text { fell and } \\
\text { sustained a } \\
\text { serious }\end{array}$ & $\begin{array}{l}\text { Parametric } \\
\text { testing to } \\
\text { determine } \\
\text { distribution } \\
\text { of costs } \\
\text { and LOS. } \\
\text { Two } \\
\text { methods of } \\
\text { analysis } \\
\text { were used, } \\
\text { regression } \\
\text { (univariate } \\
\text { and multi- }\end{array}$ & $\begin{array}{l}\text { Multivariate analysis } \\
\text { indicated } \$ 13,316 \text { more costs } \\
\text { due to serious injury fall } \\
(\mathrm{p}<.01 ; 95 \% \mathrm{CI}, \$ 1,395- \\
\$ 35,561) \text { and that these } \\
\text { fallers stayed } 6.3 \text { days longer } \\
\text { than nonfallers ( } \mathrm{p}<.001 ; 95 \% \\
\mathrm{CI}, 2.4-14.9) \text {. Univariate } \\
\text { analysis indicated fallers } \\
\text { with serious injury were } \\
\text { more likely to have diabetes } \\
\text { with organ damage, } \\
\text { moderate to severe renal }\end{array}$ \\
\hline
\end{tabular}




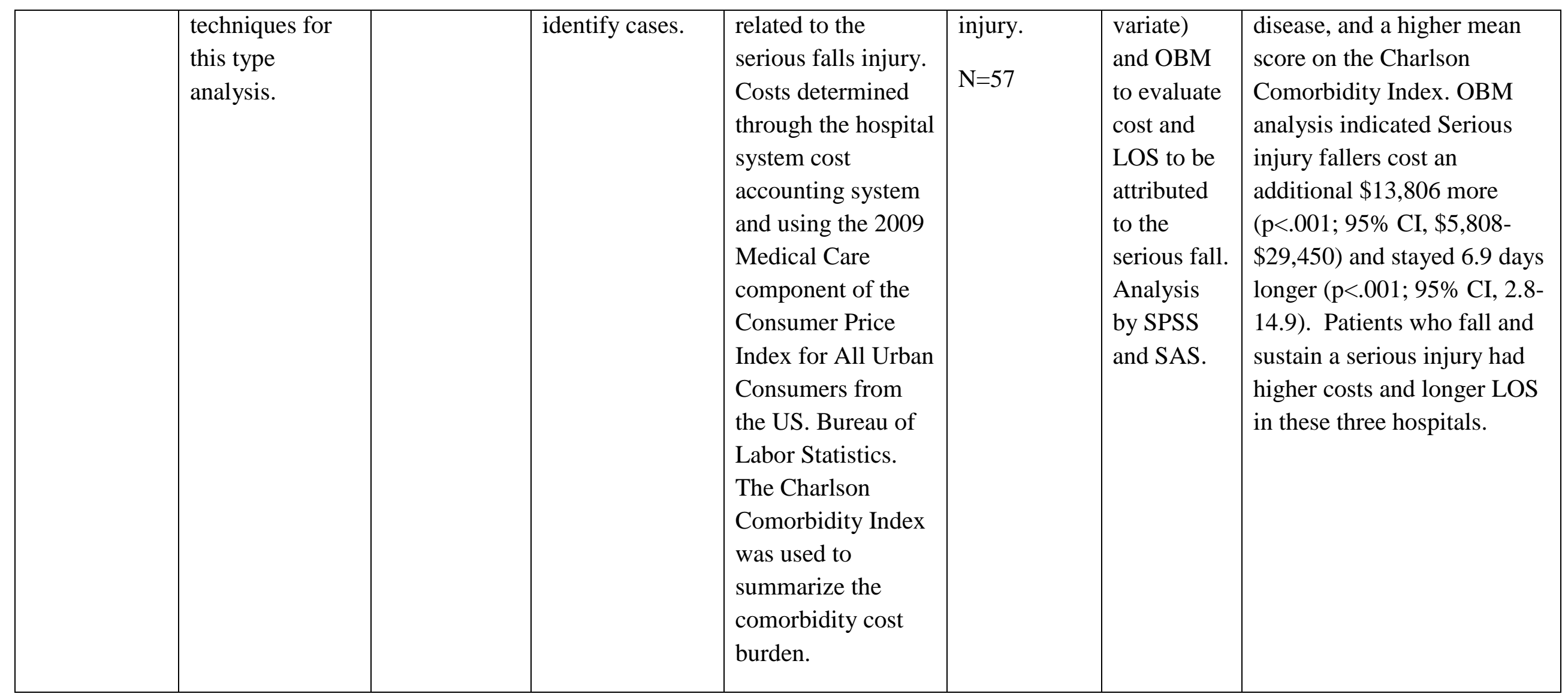




\section{Appendix C:}

Figure 2: Social Marketing Planning Process 


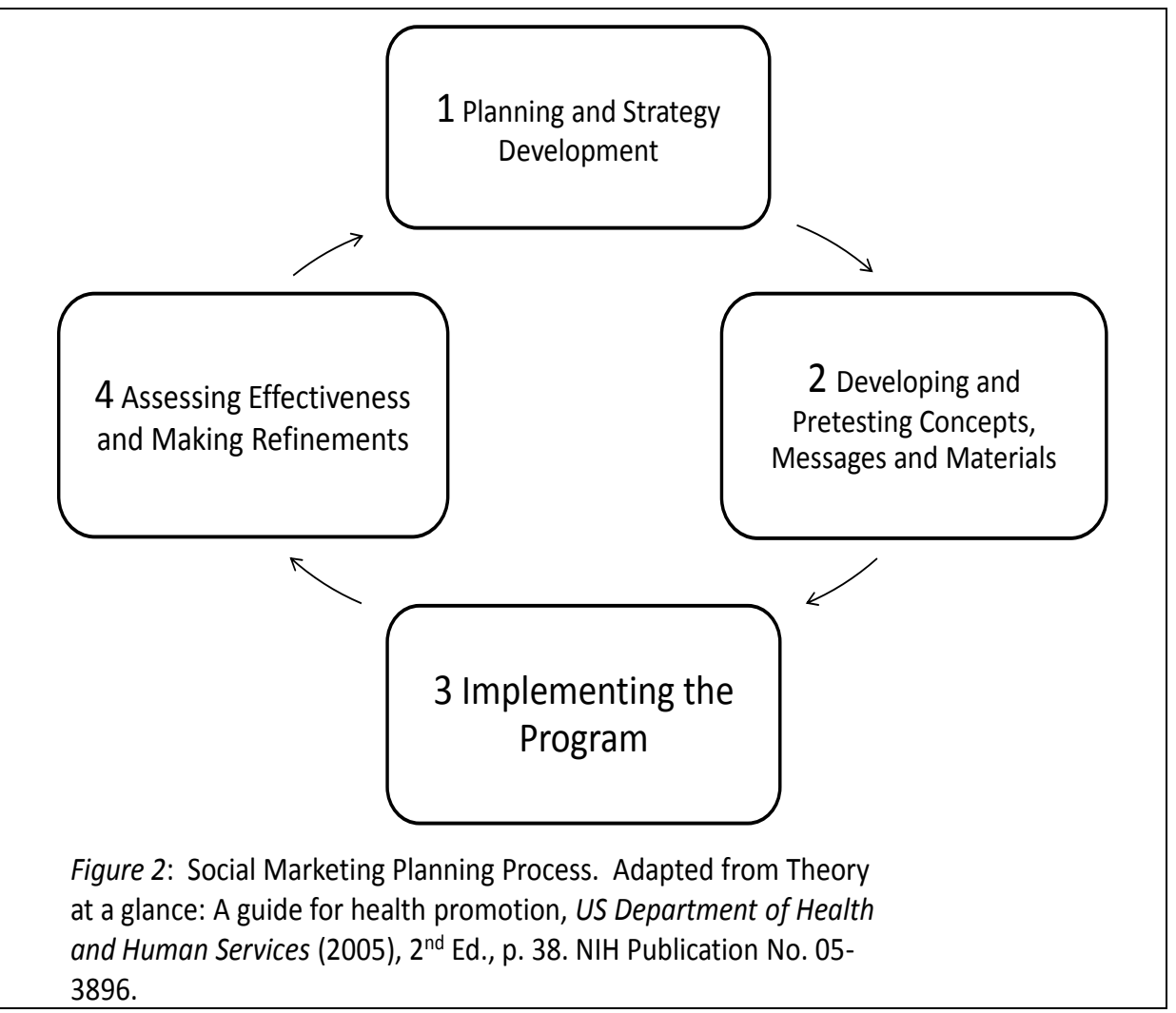


Appendix D:

Content Outline for Educational Video 


\section{Content Outline for Educational Video \\ Preventing Falls in an Acute Care Setting Through \\ Patient and Family Education \\ Capstone Study Project}

I. Introduction

a. Falls in the hospital do occur and can cause injuries, longer stay in the hospital, need for placement in nursing homes, and death (CDCP, 2005; Currie, 2008)

b. Nationwide in U.S. hospitals within one year:

i. Of 37 million patients hospitalized per year in the US, over one million patients may fall in hospitals (Currie, 2008)

ii. 90,000 patients who fall have serious injuries such as cuts, broken bones, or head injuries (Currie, 2008)

iii. About 11,000 of patients who have a serious injury from a fall die (Currie, 2008)

c. The Center for Disease Control and Prevention reports that of older adults who fall: (CDCP,2005)

i. One in five who break their hip from falling will die within one year

ii. $46 \%$ of falls resulting in death were due to traumatic brain injury

d. In the hospital falls are the most frequently occurring adverse event (Currie, 2008)

e. Longer stays in the hospital can be from six to 12 days after a fall (Bates, Pruess, Souney, \& Platt, 1995; Wong et al., 2011)

f. Hospitals and patients working together to prevent falls have been able to reduce the numbers of falls (ICSI, 2010)

II. Risks for falling in the hospital

a. All patients who are in the hospital are at risk for falling, but increased age has been shown to be a factor for increased risk (Currie, 2008; Hitcho, et al., 2004; Krauss et al., 2007)

b. Illness requiring hospitalizations may result in:

i. New medications, with new side effects that the patient is not accustomed to (Hitcho, et al., 2004)

1. Dizziness

2. Lowered blood pressure and pulse 
3. Need to go to the bathroom more frequently

4. Confusion

ii. Unexpected weakness and loss of balance when getting up to walk (Carroll, Dykes, \& Hurley, 2010)

c. Unfamiliarity of the hospital (Hitcho et al., 2004; Tzeng \& Yen, 2009)

i. Bed may be at a different height than at home

ii. A walker or cane not being near by

iii. May have equipment with tubes in use

iv. Needing to wait for a nurse to get up

d. As many as half of all falls in the hospital are reported to happen when patients are walking to and walking back from the bathroom (Hitcho, 2004; Tzeng, 2010)

$i$. While it may be embarrassing to have a toileting accident in your bed or chair, it is better to wait for the nurse to help you get to toilet than risk getting up by yourself, falling, and breaking a bone or worse, hitting your head causing a brain injury

III. What do hospitals do to keep patients from falling (ICSI, 2010; Currie, 2008)

a. Hospitals have significantly reduced the number of patient falls by putting techniques and programs in place to prevent falls

b. Do special assessments to understand each patient's risk for falling

c. Communicate your risk to the entire care team

d. Use special equipment when needed

i. Call bells for you to call for assistance before getting up alone

ii. Special socks and footwear that prevent slipping

iii. Bed and chair alarms that remind you not to get up alone and to let staff know that you are getting up and they need to come help you

iv. In special cases the staff may use a bed that has a tent over it to keep patients from getting up without help

e. Check on you frequently to see if you need to go to the bathroom, or get up to the chair, or if you are having pain

f. Staff will stay in the bathroom with the patient if necessary

g. Keep your hospital room straightened up and keep the things you need close to you

h. Educate the patient and family to what they need to do to prevent falls

IV. What do patients need to do to not fall, they have choices

a. Using strategies to prevent falling in the hospital is a choice you can make to prevent an injury due to a fall

b. If you use a walker or cane at home, tell the nurse you need it in the hospital; use it even in your hospital room 
c. Ring the call bell for the nurse, do not try to get up by yourself

d. Remember that while the nurses and other staff may appear to be busy, they are here to assist you and keep you safe. You are not a bother, but are the number one priority (Carroll et al., 2010)

e. Remember you are ill:

i. You may be at risk for falling in the hospital regardless of your normal at home abilities for independence

ii. You may be unaware how dizzy or weak you have become due to your illness (Carroll et al., 2010)

iii. You do not know how the new medications will affect you (Hitcho et al., 2004)

iv. While you may have tended all your life to be a risk taking person, during an illness requiring you to be in the hospital is not the time to take risks (Kloseck, Cirlly, \& Gibson, 2008)

v. Staff are not trying to take away your dignity by having you use fall prevention measures, only trying to keep you safe while you are ill

f. Use the non slip footwear staff have told you to wear

g. Know that if there are alarms put on your bed or chair it is for a reminder to you to wait for a nurse and for staff to come assist you

h. You may need to be patient for a staff member to come to help you, and often minutes seem much longer that they are. Please be patient and do not get up on your own

i. When staff offer to take you to the bathroom while they are in your room, let them

j. Tell staff and family to put your things near you before they leave the room and be sure your bed is in the lowest position as they may need reminders

k. Allow your family to remind you of ways you can prevent falling while a patient

V. What families can do to prevent patient falls (VonDras \& Madey, 2004)

a. Provide messages to the patient that support fall prevention strategies

i. Injuries and death can occur

ii. Illness and new medications may make them dizzy and weak

iii. Dangerous trying to go to bathroom alone; it is $O K$ to have an accident because you are sick. Nurses are here and trained to take care of this, and do so everyday

iv. Nurses will tell them what it is safe and not safe for them to do based on how at risk they are to fall 
v. Use the call bell which does not bother the staff and nurses, that is why they are there

vi. Wear special footwear to not slip

vii. Encourage patient not to take risks while so ill as to be in the hospital

viii. Remind the patient that they can help prevent falling and getting injured by following the instructions of the nurse and staff

ix. Do not get the patient up by yourself

$\mathrm{x}$. Do not leave the room cluttered when you step out

xi. Put things the patient might need within reach

VI. Family Member Interview

a. Describes their experience of losing a parent as result of a fall

b. Encourages autonomy and dignity to prevent falling

Note: Red italicized type indicates changes related to patient feedback during pretesting of messages 
Appendix E:

Content of Falls Education Brochure 
Your safety is our priority!

Each year across the nation, thousands of patients fall during their hospital stay. Many of those falls cause a patient injury. Falls can increase a patient's hospital stay by 6 to 12 days and may lead to a nursing home or rehab placement.

Your healthcare team has leamed that simple changes and teamwork between patient, family, and staff can result in a safe, positive experience.

Why are hospitalized patients at a higher risk for falls?

- Experiencing side effects of new medications

- Weakness from illness, lack of sleep and hospitalization

- Environmental risks, such as oxygen tubing and IV poles

- Adjustments to new medical condition

- Recovering from recent surgery or other procedures

If you have any of these risk factors for falls, your nurse may.

1. Use alams that tell staff you have forgotten to use your call bell and are getting out of bed

2 Assist you to and from the bathroom

3. Remain with you while you're using the bathroom

To help prevent a fall, $\mathrm{RMH}$ will:

- Maintain a safe and clutter-free environment

- Provide slip resistant footwear

- Respond quickly to call bells and bed alarms

- Supply walkers or other assistive devices

- Check on you frequently and assist you to the bathroom

- Ensure the bed is in a low position with side rails up

- Offer help with tubes and equipment
If you're considered to be someone who's at high risk of falling you will wear a special armband and we'll place a sign on your room door. This alerts staff to your risk of falling."

You can help prevent a fall by:

- Understanding that when you are sick you night not be as strong or self-supporting as when you're well.

- Ringing the call bell for any needs.

- Asking for help. We are never too busy to assist you!

- Reminding us if you cannot reach what you need

- Telling your nurse or doctor if you are experiencing any dizziness, weakness or drowsiness

- Changing positions slowly

- Using adequate lighting

- Being aware that most falls $\propto c c u r$ while patients are walking to the bathroom. Remember to use your call bell!

- Educating us about devices you use at home

Your family can help prevent falls by:

- Asking staff before assisting you out of bed

- Encouraging you to ask for help.

- Reassuring you that you're not bothering the staff by using the call bell

- Communicating with staff any safety concems you may have

- Notifying staff if you are leaving the room, so we can provide safety measures

- Making sure call bell and personal belongings are within easy reach

"In ovry high-risk situations, a special enclosad bod may be recomincended to prevent the patient from gocting out of bed. 
Appendix F:

Post Fall Huddle Report 


\section{Post-Fall Huddle Form}

ection A: Fall Event Details (to be filled out by RN)

ate of Fall: Time of Fall:

Pre-Fall Estimated Discharge Date:

lepartment/Nursing Unit where fall occurred:

[ad the patient been identified as a fall risk: $\square$ Yes $\square$ No

Then was the last time the patient was rounded on?

Thich of the following were assessed during rounds? $\quad \square$ Pain $\quad \square$ Potty $\square$ Positioning $\square$ Placement o ection B: Post-Fall Huddle SBAR (within 15-30 minutes of a fall, gather all members of the team (including pat nd housekeeper) available on the shift and day the fall occurred to complete the following questions):

ITUATION

\begin{tabular}{l} 
Did fall occur during change of shift: $\square$ Yes \\
Vhere did the fall occur: $\square$ Patient room $\square$ Patient bathroom $\square$ Hallway $\square$ Other: \\
\hline nvironmental Assessment Completed? $\square$ Yes $\square$ No Hazardous Footwear? $\square$ Yes $\square$ No
\end{tabular}

rip Hazards? $\square$ None $\square$ Clothing $\square$ Shoes (ill-fitting/untied laces) $\square$ Tubing/Cord

$\square$ Obstructed path to bathroom $\square$ Other:

vidence of slippery floor? $\square$ Yes $\square$ No

Vas lighting in the room adequate? $\square$ Yes $\square$ No

Vas there equipment malfunction? $\square$ No $\square$ Call bell

What do you think the patient was doing at the time of the fall?

] Trying to get to the bathroom $\square$ Reaching for something

J Trying to get elsewhere (

ACKGROUND

all risk factors (check all that apply)

Impaired mobility

Impaired mentation

Impaired/altered elimination patterns (nocturia, urgency, frequency, diarrhea, incontinence, laxative, bowel 1

Impaired communication/sensory (vision, hearing, neuopathy)

Impaired vital signs (fever, slow or fast heart rate, low blood pressure)

Prior fall history (at home, previous facility, during this stay)

Medications administered within 8 hours prior to fall:

\begin{tabular}{|c|c|c|c|c|}
\hline None & PCA & Opiates & Anticonvulsants & Antihyperten \\
\hline Antiarrhythmics & Diuretics & Hypnotics & Sedatives & Laxatives \\
\hline Antidepressants & $\square$ Benzos & $\square$ Antipsychotics & Antihistamines & Antiparkinsor \\
\hline Alzheimer drugs & \multicolumn{2}{|c|}{ Is the patient on anticoagulants? } & $\square$ No & \\
\hline Diagnosis-related & Hypotension & Hypoglycemia & Neurological Disorder & Cardiac \\
\hline
\end{tabular}

hat did the patient/family report was the reason for the fall?

\section{SSESSMENT}

ijury: $\square$ None $\square$ Minor: $\square$ Moderate: $\square$ Severe:

\section{ECOMMENDATION}

hat can we do to prevent this from happening again? Care plan recommendations:

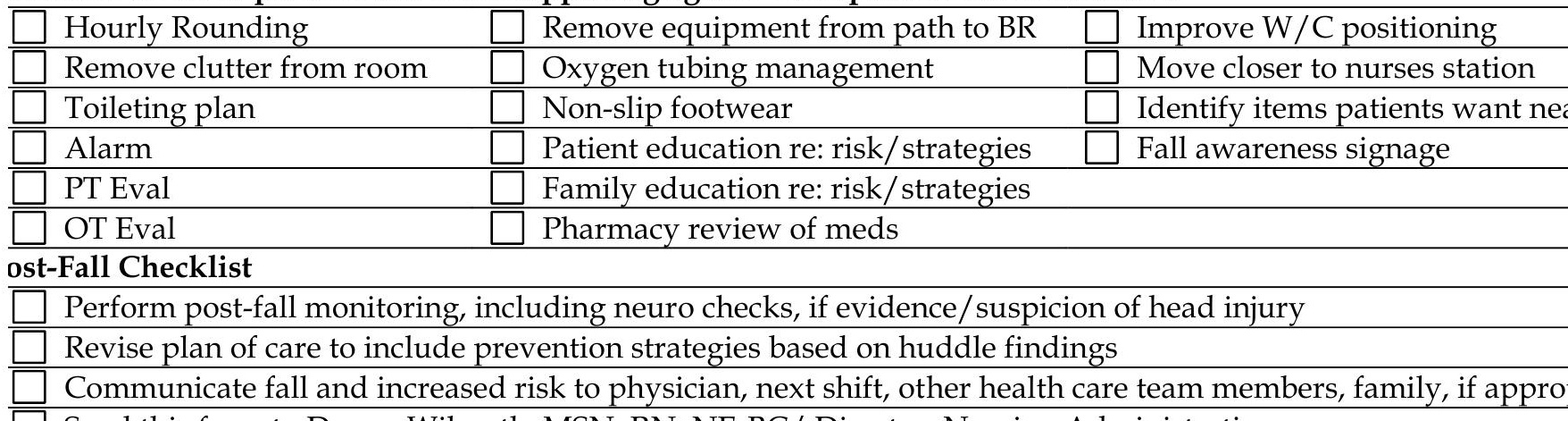


Appendix G:

Informed Consent for Intervention Group 


\section{Informed Consent for Study Inclusion Form}

\section{Intervention Group}

\section{Study Name: Preventing Falls in an Acute Care Setting Through Patient and Family Education}

\section{Dear Patient:}

Patients in the hospital are at risk of falling, and some who fall experience serious injuries. There have been studies that tell us that certain factors such as age, new medications, dizziness, and weakness due to illness put patients at particular risk to fall while in the hospital.

At times Rockingham Memorial Hospital (RMH) makes changes in the ways care is provided and monitors these changes to decide if they improve the quality and safety of patients. The research we are asking you to take part in is to reduce the risk of falling for patients in the hospital by patients and family members watching a video on preventing falls. Any patient admitted to RMH receives fall prevention efforts, including education on how patients can reduce their own risk of falling. You will be part of a group of patients during a three month period who receives the usual efforts by staff to prevent falls which includes a falls education brochure. In addition to the brochure usual efforts include such things as unit orientation and a fall risk assessment tool. Usual care efforts will include interventions based on the patients individual fall risk score and may include yellow slip resistant socks, yellow arm bands, and bed alarms. However for this part of the study we are asking you and one of your family members, if available, to also watch a video on falls prevention education. Another group of patients during a previous three month period received the same care as you but neither those patients nor their families viewed the video education. Date Date 
We will be monitoring the number of patient falls, and the injuries that occur from those falls, for those who participate in the study. We are trying to determine if education provided to patients and family members decrease the number of patient falls and patient injuries related to falls.

The purpose is to try different ways of education to decrease your risk of falling while a patient in the hospital. After you and your family member (if they are available) watch the video, a nurse will ask you one thing that you can do to prevent falling while a patient.

There are no known risks to patients or family members who accept being involved in this study. Any reports or publications related to this study will not identify any personal information about you or your family.

We would like your permission to have you participate in this study while you are a patient on the study unit. We believe you may benefit from participation in this study by a decreasing your risk of falling, experiencing an injury due to falling, and increasing your knowledge of your own risk for falling. If you are willing to be part of this study please read all this information, complete the required blanks, and sign indicating your permission on the bottom of this consent form.

Name of

Patient

I state that I am at least 18 years of age and wish to participate in this study being conducted by RMH. Date:

Name of

Family or Friend 
I state that I am at least 18 years of age and wish to participate in this study being conducted by RMH.

Family or Friend Initials Date

All the information collected in this study is confidential. I understand that the data I provide may be grouped with other patient data for reporting and presenting and that my name or other specific private information will not be used.

I understand that I am free to ask questions or withdraw from participation at any time and without penalty.

RMH does not provide any medical or hospitalization insurance or compensation for being involved in this study and RMH does not agree to assume any responsibility for falls which occur during this study participation.

If you have any questions about your rights as a research study participant or wish to report a research related injury, contact:

Stewart Pollock, MD, Chairman of the IRB at Rockingham Memorial Hospital 2010 Health Campus Drive, Harrisonburg, VA, 22801.

Dr. Pollock's phone number is 540-689-1000.

If you have questions about this particular study, contact:

Donna S. Hahn, MSN, RN, NEA-BC, Vice President/Chief Nurse Executive, 2010 Heath Campus Drive, Harrisonburg, VA, 22801.

Ms. Hahn's phone number is 540-689-1200.

Subject Name:

Subject Signature: 
Date Signed:

Patient Initials____ Date

Family or Friend Initials_____Date

If Applicable:

Family or Friend Name:

Family or Friend Signature:

Date Signed:

Witnessed

By:____ Date:

Patient Initials____ Date

Family or Friend Initials_____ Date 
Appendix H:

Informed Consent for Comparison Group 


\section{Informed Consent for Study Inclusion Form}

\section{Comparison Group}

\section{Study Name: Preventing Falls in an Acute Care Setting Through Patient and Family Education}

\section{Dear Patient:}

Patients in the hospital are at risk of falling, and some who fall experience serious injuries. There have been studies that tell us that certain factors such as age, new medications, managing tubes and equipment, and weakness due to illness put patients at particular risk to fall while in the hospital.

At times Rockingham Memorial Hospital (RMH) makes changes in the ways care is provided and monitors these changes to decide if they improve the quality and safety of patients. The research we are asking you to take part in is to reduce the risk of falling for patients in the hospital by comparing the way you are educated on prevention of falls while a patient. Any patient admitted to RMH receives fall prevention efforts, including education on how patients can reduce their own risk of falling. However, on the unit you are admitted to we are researching how the educational brochure you receive compares to a video education tool that another group of patients and family members will receive to reduce the risk of patient falls.

You will be part of a group of patients during a three month period who receives the usual efforts by staff to prevent falls which includes a falls education brochure. In addition to the brochure usual efforts include such things as unit orientation and a fall risk assessment tool. Usual care efforts will include interventions based on the patients individual fall risk score and may include yellow slip resistant socks, yellow arm bands, and bed alarms. Date 
Another group of patients during a different three month period will receive the same care as you but will be asked, along with family, to view a falls prevention video.

We will be monitoring patient falls who participate in the study to determine if the video decreases the number of patient falls and patient injuries related to falls. The purpose is to try different ways of education, compare them, and to then in the future use the method that works best to reduce patient falls.

There are no known risks to patients or family members who accept being involved in this study. Any reports or publications related to this study will not identify personal information.

We would like your permission to have you participate in this study while you are a patient on the study unit. We believe you may benefit from participation in this study by a decreasing your risk of falling, experiencing an injury due to falling, and increasing your knowledge of your own risk for falling. If you are willing to be part of this study please read all this information, complete the required blanks, and sign indicating your permission on the bottom of this consent form.

Name of

Patient

I state that I am at least 18 years of age and wish to participate in this study being conducted by RMH.

Patient Initials Date:

All the information collected in this study is confidential. I understand that the data I provide may be grouped with other patient data for reporting and presenting and that my name or other specific private information will not be used. Date: 
I understand that I am free to ask questions or withdraw from participation at any time and without penalty.

RMH does not provide any medical or hospitalization insurance or compensation for being involved in this study and $\mathrm{RMH}$ does not agree to assume any responsibility for falls which occur during this study participation.

If you have any questions about your rights as a research study participant or wish to report a research related injury, contact:

Stewart Pollock, MD, Chairman of the IRB at Rockingham Memorial Hospital 2010 Health Campus Drive, Harrisonburg, VA, 22801.

Dr. Pollock's phone number is 540-689-1000.

If you have questions about this particular study, contact:

Donna S. Hahn, MSN, RN, NEA-BC, Vice President/Chief Nurse Executive, 2010 Heath Campus Drive, Harrisonburg, VA, 22801. Ms. Hahn's phone number is $540-689-1200$.

Subject Name:

Subject Signature:

Date Signed: 
Witnessed

By:

Date: 
Appendix I:

Investigational Review Board Approval 


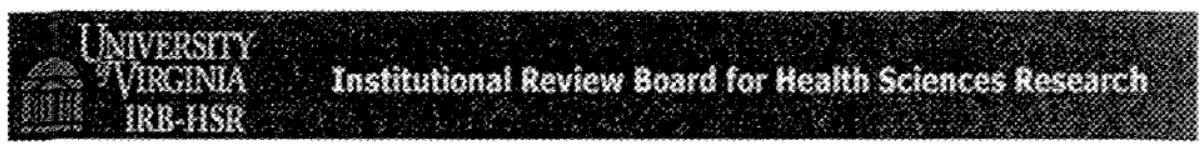

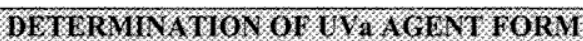

\section{INFORMATION ABOUT THIS FORM}

- This form is to determine if UVa personel are or are not considered to be working as an Agent* for UVa on this project.

- If it determined that UVa personnel are considered to be working as an Agent* for UVa the study team will be required to submit an additional submission to the IRB-HSR, unless the project is determined to not involve human subject research. See Deternination of Xfuman Subject Research form

*Agent-all individuals fincluding students) performing institutionally designated activities or exercising insfitutionally delegated authority or responsibility.

Enter responses electronically. Prior to obtaining signatures, email the completed form to

IRBHSR@irginia.edu for pre-review. An IRB staff member will reply with any changes to be made.

Name of Individual to be Working on Project:

Email:

Phone:

UVa Messenger Mail Box \#

Project/Protocol Title if Known:

Explain your role in the project: (200 words or less)

Explain the reason for traveling to the outside institution.

1. Answer the following questions:

was involved in the design of this research project.

Yes $\triangle$ No A UVa IRB has approved this research. IRB-HSR \#

$\square$ Yes $\triangle$ No Funding to conduct this research will come from UVa.

$\square$ Yes $\triangle$ No The only reason I am traveling to this outside institution is to work on this research.

$\triangle$ Yes $\square$ No Working on this research is required for my degree program.

\section{I confirm that}

$\square$ Yes $\square$ No I am a student, employee and/or faculty member of the University of Virginia.

Yes $\square$ Xo The project has or will have IRB approval from the outside institution and I will be listed on their application as personnel conducting the study.

$\square$ Yes $\square$ No My work on this project will be overseen by the Principal Investigator and the IRB at the outside institution.

OR

3. I confirm that

Website: http://www.virginia.edu/vpr/irb/hsrfindex.htm/

Phone: 434-924-2620 Fax: 434-924-2932 Box 800483

Version date: $02-18-12$

Page 1 of 2 
QYes $\square$ No I designed this research, I am a student at UVa but am employed by another institution. All subjects will be enrolled at this outside institution, and the research will be overseen by their IRB. There is no funding for this study. ATTACH COPY OF OUTSIDE IRB APPROVAL.

Bominas s rain

Printed Name of Person Completing this Form

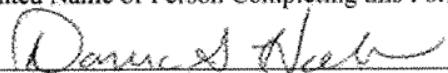

Signature of Person Completing this Form

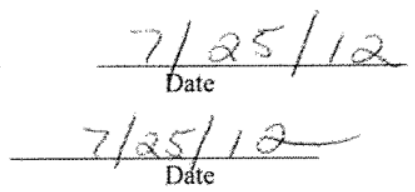

Dáte

\section{FOR TRB-HSR ORFICE USE ONLY}

$\bigotimes$ UVa personnel are not considered to be working as an Agent for UVa on this project.

No approvals from the UVa IRB-HSR are required.

$\square$ UVa personnel are considered to be working as an Agent for UVa on this project.

Submit a research application to the UVa IRB-HSR.

Swaie 2lffmax IRB-HSRDiretor

Signature of IRB Chair, Director or Designee

$7 / 26 / 12$




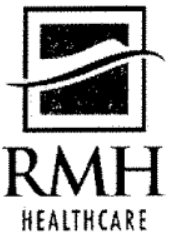

July 10,2012

Ms. Donna Hahn

Rockingham Memorial Hospital

2010 Health Campus Drive

Harrisonburg VA 22801

Donna,

\section{RE: Preventing Falls in an Acute Care Setting Through Patient \& Family Education}

At the convened meeting of the Rockingham Memorial Hospital Institutional Review Board on July 10,2012 , the above referenced protocol dated $6 / 13 / 12$ and the informed consent, RMH Version 1 dated 6/13/12 were unanimously approved by the full board (10 votes for, 0 against, 0 abstentions) with the following modifications:

- Define "usual care" in the protocol and consent form.

- Add that the intervention group also gets "usual care".

- Once the video has been completed (late August), a subgroup of the IRB needs to review it.

The study will expire on July 10,2013. At that time, the annual protocol will be reviewed for continuing approval. Any serious adverse events will require reporting per the Rockingham Memorial Hospital IRB Guidelines.

Sincerely,

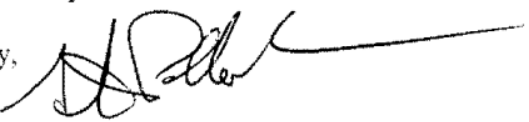

Stewart Pollock, MD

Chairman

RMH Healthcare

Institutional Review Board

Get well, Live well $• 540.689 .1000 \cdot 2010$ Health Campus Drive, Harrisonburg, Virginia 2280 • RMHOnline.com 


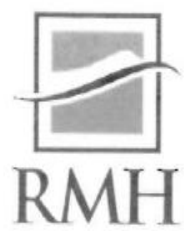

HEALTHCARE

October 8, 2013

\author{
Ms. Donna Hahn \\ Rockingham Memorial Hospital \\ 2010 Health Campus Drive \\ Harrisonburg VA 22801
}

Donna,

\title{
RE: Preventing Falls in an Acute Care Setting Through Patient \& Family Education
}

At the convened meeting of the Rockingham Memorial Hospital Institutional Review Board on November 13, 2012, an amendment dated 11/9/12 to the above referenced protocol asked for the addition of other specifically trained Patient Care Technicians to obtain informed consent for the study. This amendment was approved by the full board ( 7 votes for, 0 against, 0 abstentions).

Dr. Hahn was excused and left the room before the voting

Donna Hahn, RN contacted Kristin Payne, RMH IRB, on October 8, 2013 requesting a copy of the amendment approval letter. It was discovered that an approval letter had not been submitted to Ms. Hahn for her records.

The study was closed to accrual, follow-up only on July 9, 2013. Until follow-up is concluded, the study will be renewed on or before July 10 of each year. Any serious adverse events will require reporting per the Rockingham Memorial Hospital IRB Guidelines.

Sincerely,
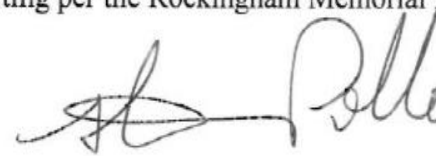

Stewart Pollock, MD

Chairman

RMH Healthcare

Institutional Review Board 
Appendix J:

Author Guidelines

Journal of Nursing Care Quality 
Journal of Nursing Care Quality

Online Submission and Review System

Instructions for Authors (this page)

Copyright Transfer (PDF)

Reprint Ordering

Permissions Requests

Permission Form (PDF)

Permission to Acknowledge form

Journal of Nursing Care Quality Online Submission and Review System

\section{Editorial Purpose}

The primary objective of the Journal of Nursing Care Quality (JNCQ) is to provide practicing nurses and nurses in leadership roles with useful information about patient safety, quality care, and the application of quality principles in the clinical setting. Articles in the $J N C Q$ address patient safety, innovative and effective approaches to improving quality and safety in healthcare, research on quality care, and evidence-based practice in nursing. The $J N C Q$ provides a forum for the discussion of patient safety issues and "real world" implementation of quality-related activities.

\section{Manuscript Review}

The $J N C Q$ is a peer-reviewed journal. Published manuscripts have been reviewed, selected, and developed with the guidance of the editorial board. Manuscript content is assessed for relevance, accuracy, and usefulness to practicing nurses, nurses in leadership roles, and other healthcare providers involved in evaluating and improving safety and quality of care. Manuscripts are reviewed with the understanding that neither the manuscript nor its essential content has been published or is under consideration by others.

\section{Authorship Responsibility}

All persons designated as authors should qualify for authorship. Each author should have contributed significantly to the conception and design of the work and writing the manuscript to take public responsibility for it. The editor may request justification of assignment of authorship. Names of those who contributed general support or technical help may be listed in an acknowledgment placed after the narrative and before the references.

\section{Query Letters}


Although not necessary, query letters allow the editor to indicate interest in, and developmental advice on, manuscript topics.

\section{Manuscript Preparation}

Prepare manuscripts according to the American Medical Association (AMA) Manual of Style (10th ed) $10^{\text {th }}$ edition. The maximum manuscript length is approximately 18 pages including tables, figures, and references. As a general rule, an 18-page paper should have no more than 3 figures or tables.

For manuscripts describing quality improvement studies, follow the Standards for Quality Improvement Reporting Excellence (SQUIRE) guidelines at http://www.squirestatement.org/guidelines. (see also Oermann MH. SQUIRE guidelines for reporting improvement studies in healthcare: Implications for nursing publications. J Nurs Care Qual.2009; 24(2):91-95 For some manuscripts, it may not be appropriate to include every guideline item, but authors should consider each item in preparing their papers for submission. The "Discussion" section should include nursing implications.

\section{Format}

Double space the manuscript using a 12-point type size, any font style.

Add page numbers in the upper right-hand corner of each page.

Left justify all text, including headings.

Divide the text into main sections by inserting subheadings.

All headings are flush left, in bold, and distinguished by level as follows:

FIRST-LEVEL HEADING (CAPITALIZED ON SEPARATE LINE)

Second-level heading (Regular on separate line)

Third-level heading (Italic on separate line)

Do not use running headers or footers.

\section{Title/Author Biography Page}

Information for the title/author biography page is placed in a 1-page Word file. This information should not be placed in any other file. This title page Word file should contain only the:

Title of the manuscript;

1. Author(s) names and credentials (highest earned credential only, followed by RN, and certifications);

2. Author(s) affiliation(s): job title, department, institution, city, state, country; 
3. Corresponding author: For publication, it is preferable to use a work address. You must include an e-mail address at the end of your mailing address; and

4. Funding information and other disclaimer or disclosure information. Include disclosure of funding received for this work from any of the following organizations: National Institutes of Health (NIH); Wellcome Trust; Howard Hughes Medical Institute (HHMI); and other(s).

\begin{abstract}
Include an abstract of 50 to 75 words that stimulates readers' interest in the topic and states what they will learn from reading the article.
\end{abstract}

\title{
Tables and Figures
}

Tables and figures, if any, should be saved as individual files. All tables must be numbered consecutively with Arabic numbers and have a title. All figures must be numbered consecutively with Arabic numbers and have a title. Tables and figures must be cited in numerical order in the text. All figures and other artwork should be submitted in black and white.

\section{A) Creating Digital Artwork}

1. Learn about the publication requirements for Digital Artwork: http://links.lww.com.proxy.its.virginia.edu/ES/A42

2. Create, Scan and Save your artwork and compare your final figure to the Digital Artwork Guideline Checklist (below).

3. Upload each figure to Editorial Manager in conjunction with your manuscript text and tables.

\section{B) Digital Artwork Guideline Checklist}

Here are the basics to have in place before submitting your digital artwork:

- $\quad$ Artwork should be saved as TIFF, EPS, or MS Office (DOC, PPT, XLS) files. High resolution PDF files are also acceptable. 
- Crop out any white or black space surrounding the image.

- Diagrams, drawings, graphs, and other line art must be vector or saved at a resolution of at least $1200 \mathrm{dpi}$. If created in an MS Office program, send the native (DOC, PPT, XLS) file.

- Photographs, radiographs and other halftone images must be saved at a resolution of at least $300 \mathrm{dpi}$.

- Photographs and radiographs with text must be saved as postscript or at a resolution of at least $600 \mathrm{dpi}$.

- Each figure must be saved and submitted as a separate file. Figures should not be embedded in the manuscript text file.

\section{Remember:}

- Cite figures consecutively in your manuscript.

- Number figures in the figure legend in the order in which they are discussed.

- Upload figures consecutively to the Editorial Manager web site and enter figure numbers consecutively in the Description field when uploading the files.

\section{References}

Prepare references according to the style used in the AMA Manual of Style (10th ed.). References should be typed double-spaced and placed at the end of the manuscript. They should be numbered consecutively in the order in which they are cited in the text. Whenever a reference is repeated in the text, it uses the same reference number each time. Journal titles should be abbreviated according to the listing in the PubMed Journals database. If not listed there, journal titles should be spelled out.

\section{Examples:}

Journal article with 1 author:

Clancy CM. The promise and future of comparative effectiveness research. J Nurs Care Qual. 2010;25(1):1-4. 
Journal article with multiple authors:

Levin RF, Keefer JM, Marren J, Vetter MJ, Lauder B, Sobolewski S. Evidence-based practice improvement: merging 2 paradigms. J Nurs Care Qual.2010;25(2):117-126.

Book:

Oermann MH, Hays JC. Writing for Publication in Nursing. 2nd ed. New York: Springer;2011.

Web site:

2010 National Patient Safety Goals (NPSGs). The Joint Commission Web site. http://www.jointcommission.org/patientsafety/nationalpatientsafetygoals/. Published June 2006. Accessed May 1, 2010.

For other electronic references, follow guidelines in the AMA Manual of Style p. 63.

\section{Permissions}

Written permission must be obtained from (1) the holder of copyrighted material used in the manuscript, (2) persons mentioned in the text or acknowledgment, and (3) the administrators of institutions mentioned in the text or acknowledgment. Where permission has been granted, the author should follow any special wording stipulated by the grantor. Letters of permission must be submitted before publication of the manuscript. Permission forms are available under Files and Resources.

\section{Compliance with NIH and Other Research Funding Agency Accessibility Requirements}

A number of research funding agencies now require or request authors to submit the postprint (the article after peer review and acceptance but not the final published article) to a repository that is accessible online by all without charge. As a service to our authors, LWW will identify to the National Library of Medicine articles that require deposit and will transmit the postprint of an article based on research funded in whole or in part by the National Institutes of Health, Wellcome Trust, Howard Hughes Medical Institute, or other funding agencies to PubMed Central. The revised Copyright Transfer Agreement provides the mechanism.

\section{Conflicts of Interest}

Authors must state all possible conflicts of interest in the manuscript, including financial, consultant, institutional and other relationships that might lead to bias or a conflict of interest. If there is no conflict of interest, this should also be explicitly stated as none declared. All sources of funding should be acknowledged in the manuscript. All relevant conflicts of interest and sources of funding should be included on the title page of the manuscript with the heading "Conflicts of Interest and Source of Funding:". For example: 
Conflicts of Interest and Source of Funding: A has received honoraria from Company Z. $\mathrm{B}$ is currently receiving a grant (\#12345) from Organization Y, and is on the speaker's bureau for Organization $\mathrm{X}$ - the CME organizers for Company A. For the remaining authors none were declared.

In addition, each author must complete and submit the journal's copyright transfer agreement, which includes a section on the disclosure of potential conflicts of interest based on the recommendations of the International Committee of Medical Journal Editors, "Uniform Requirements for Manuscripts Submitted to Biomedical Journals" (www.icmje.org/update.html). The form is readily available on the manuscript submission page http://www.editorialmanager.com/jncq/ and can be completed and submitted electronically. Please note that authors may sign the copyright transfer agreement form electronically. For additional information about electronically signing this form, go to http://links.lww.com.proxy.its.virginia.edu/ZUAT/A106.

\section{Online Manuscript Submission}

All manuscripts must be submitted online through our Web-based Editorial Manager system at http://jncq.edmgr.com. Submit your manuscript according to the author instructions. You will be able to track the progress of your manuscript through the system.

First-time users: Click the Register button from the menu (on the upper banner) and enter the requested information. On successful registration, you will be sent an e-mail indicating your user name and password. Save a copy of this information for future reference.

Return users: If you have received an e-mail from us with an assigned user ID and a password, or if you are a repeat user, do not register again. Just log in. Once you have an assigned ID and a password, you do not have to re-register even if your status changes (ie, author or reviewer).

After registering as an author, log on to http://jncq.edmgr.com and select "Submit a New Manuscript." You will then:

1. Select an "article type" from the drop down menu

2. Enter the title of your manuscript

3. Add information about the author(s) of the paper

4. Enter abstract of your manuscript

5. Enter a few key words that describe your manuscript's content 
6. Enter your comments to the editor in a dialogue box, mentioning any prior query you may have had with the editor

7. Attach your various individual files containing elements of your entire manuscript. No file should contain information found in any other file:

Title/author biography page

Abstract

Manuscript text, ending with the references

As many individual files as necessary, each containing 1 table or figure.

When all files are attached, the system will prompt you to complete a process that will submit your manuscript to the editorial office. You will receive an e-mail to let you know that the journal office received your manuscript. After the review process, you will receive an e-mail letting you know the final disposition of the manuscript. You may check the status of your manuscript at any time by logging in to http://jncq.edmgr.com. Select "Submissions Being Processed."

\section{Revised Submission}

If your manuscript is accepted for publication, the revision is submitted online at http://jncq.edmgr.com. Do NOT submit your revision as a "New Submission" under the heading "New Submissions." Log in using the same user name and password. On the Author Main Menu, under the heading "Revisions," select the "Submissions Needing Revision" link, which will be the only active link.

\section{Help}

If at any time during this process you have questions, please e-mail moermann@msn.com

or marilyn.oermann@duke.edu, phone 248-568-1848 248-568-1848 FREE . The Editorial Office mailing address is Journal of Nursing Care Quality, Marilyn H. Oermann (Editor), 148 Saxapahaw Run, Chapel Hill, North Carolina 27516, USA.

\section{Copyright/Disclaimer Notice $\bullet$ Privacy Policy}




\section{Appendix J:}

Table 1: Group Demographics and Length of Stay Characteristics 
Table 1: Group Demographic and Length of Stay Characteristics

\begin{tabular}{|c|c|c|c|}
\hline \multirow[b]{5}{*}{ Variable } & Group 1 & Group 2 & \multirow[b]{5}{*}{$P$} \\
\hline & Phase 1 & Phase 2 & \\
\hline & Falls Brochure & \multirow{2}{*}{$\begin{array}{l}\text { Falls Brochure and } \\
\text { Video }\end{array}$} & \\
\hline & & & \\
\hline & $(n=100)$ & $(n=92)$ & \\
\hline Gender, $n(\%)$ & & & $>0.05$ \\
\hline Male & $36(36)$ & $36(39.1)$ & \\
\hline Female & $64(64)$ & $56(60.9)$ & \\
\hline Primary Language, & & & $>0.05$ \\
\hline$n(\%)$ & & & \\
\hline English & $100(100)$ & $91(98.9)$ & \\
\hline Spanish & $0(0)$ & $1(1.1)$ & \\
\hline Race, $n(\%)$ & & & $>0.05$ \\
\hline African American & $3(3)$ & $3(3.3)$ & \\
\hline Caucasian & $96(96)$ & $84(91.3)$ & \\
\hline Hispanic & $1(1)$ & $1(1.1)$ & \\
\hline Other & $0(0)$ & $4(4.3)$ & \\
\hline Age, Mean (SD) & 74.05 (7.933) & $74.16(8.499)$ & $>0.05$ \\
\hline LOS, Mean (SD) & 3.33 (3.77) & 3.77 (3.762) & $>0.05$ \\
\hline
\end{tabular}




\section{References}

AHRQ, Agency for Healthcare and Research Quality, 20 tips to help prevent medical error. (2011). Retrieved 11, 2011, from http://www.ahrq.gov/consumer/20tips.pdf

American Medical Association Foundation \& American Medical Association, (2007).

Reducing the risk by designing a safer, shame-free health care environment.

Retrieved 11, 2013, from http://www.ama-assn.org/resources/doc/amafoundation/hl_monograph.pdf

ANCC, American Nurses Credentialing Center. Magnet program overview. (2012).

Retrieved March, 2012, from

http://www.nursecredentialing.org/Magnet/ProgramOverview.aspx

American Nurse Credentialing Center (2008), Recognizing Nursing Excellence

Application Manual, Magnet Recognition Program. Silver Springs, MD

Ajzen, I. (1991). The theory of planned behavior. Organizational Behavior and Human Decision Processes, 50, 179-211.

Bates, D. W., Pruess, K., Souney, P., \& Platt, R. (1995). Serious falls in hospitalized patients: Correlates and resource utilization. The American Journal of Medicine, 99(2), 137-143. doi: 10.1016/S0002-9343(99)80133-8 
Boase, S., Kim, Y., Craven, A., \& Cohn, S.(2011). Involving practice nurses in primary care research: the experience of multiple and competing demands. Journal of Advanced Nursing 68(3), 590-599.

Carroll, D. L., Dykes, P. C., \& Hurley, A. C. (2010). Patients' perspectives of falling while in an acute care hospital and suggestions for prevention. Applied Nursing Research, 23, 238-241.

Center for Disease Control. National center for injury prevention and control cost of fall injuries in older persons in the United States, 2005. (2011). Retrieved 5/6, 2011, from http://www.cdc.gov/injury/index.html

CMS, Center for Medicare and Medicaid Services. Hospital acquired conditions. (2011). Retrieved 9/11, 2011, from https://www.cms.gov/hospitalacqcond/06_hospitalacquired_conditions.asp

Coe, R. (2002, September). It's the effect size, stupid: What effect size is and why it is important. Paper presented at the Annual Conference of the British Educational Research Association, University of Exeter, England.

Cohen, J., (1992). A power primer. Psychological Bulletin, 112(1), 155-159.

Currie, L., (2008). Fall and injury prevention. In R. G. Hughes (Ed.), Patient safety and quality: An evidence-based handbook for nurses (pp. 195-250). Rockville, MD: 
Agency for Healthcare Research and Quality, US Department of Health and Human Services.

Degelau J, Belz M, Bungum L, Flavin PL, Harper C, Leys K, Lundquist L, Webb B. Institute for Clinical Systems Improvement. Prevention of Falls (Acute Care). Updated April 2012. Retrieved 10/19, 2013

Durlak, J. (2009). How to select, calculate, and interpret effect sizes. Journal of Pediatric Psychology, 34(9) pp. 917-928.

Dykes, P. C., Carroll, D. L., Hurley, A. C., Benoit, A., \& Middleton, B. (2009). Why do patients in acute care hospitals fall? Can falls be prevented? Journal of Nursing Administration, 39(6), 299-304.

Dykes, P. C., Carroll, D. L., Hurley, A., Lipsitz, S., Benoit, A., Chang, F., Middleton, B. (2010). Fall prevention in acute care hospitals. JAMA: The Journal of the American Medical Association, 304(17), 1912-1918. doi:10.1001/jama.2010.1567

Edberg, M. (2007). Individual health behavior theories. In R. Reigelman, Essentials of Health Behavior: Social and Behavioral Theory in Public Health (pp.35-49). Sudbury, MA: Jones \& Bartlett Learning.

Envision, inc., Leaders in health care education. Partners in care...fall prevention for patient education. Retrieved 4/22, 2012, from http://www.envisioninc.net/index.php/programs/details/fall_prevention_package/ 
Ferguson, C. J. (2009). An effect size primer: a guide for clinicians and researchers. Professional Psychology: Research and Practice 40(5), 532-538.

Haines, T. P., Hill, A. M., Hill, K. D., McPhail, S., Oliver, D., Brauer, S., Beer, C. (2011). Patient education to prevent falls among older hospital inpatients: A randomized controlled trial. Archives of Internal Medicine, 171(6), 516-524.

Hill, A., McPhail, S., Hoffmann, T., Hill, K., Oliver, D., Beer, C., Haines, T. P. (2009). A randomized trial comparing digital video disc with written delivery of falls prevention education for older patients in hospital. Journal of the American Geriatrics Society, 57(8), 1458-1463. doi:10.1111/j.1532-5415.2009.02346.x

Hitcho, E. B., Krauss, M. J., Birge, S., Dunagan, W. C., Fischer, I., Johnson, S., Fraser, V. J. (2004). Characteristics and circumstances of falls in a hospital setting. JGIM: Journal of General Internal Medicine, 19(7), 732-739. doi:10.1111/j.15251497.2004.30387.x

Horsburgh, D. (2003). Evaluation of qualitative research. Journal of Clinical Nursing, $12,307-312$.

Howie-Esquivel, J., White, M., Carroll, M., \& Brinker, E. (2011). Teach-back is an effective strategy for educating older heart failure patients. Journal of Cardiac Failure, 17(8, Supplement), S103. 
Institute for clinical systems improvement (ICSI), Health care protocol: Prevention of falls (acute care). (2010). Retrieved 5/6, 2011, from http://www.icsi.org/guidelines_and_more/protocols_patient_safety_reliability_pr otocols/falls_acute_care_prevention_of_protocol_falls_acute_care_prevent ion_of_protocol_24254.html

Institute for Healthcare Improvement (IHI). Always use teachback. Retrieved 11/9, 2013, from http://www.ihi.org/knowledge/Pages/Tools/AlwaysUseTeachBack!.aspx

Kloseck, M., Crilly, R. G., \& Gibson, M. (2008). Can personality theory help us understand risk of falls? Journal of Rehabilitation Research \& Development, 45(8), 1125-1134.

Kornburger, C., Gibson, C., Sadowski, S., Maletta, K., \& Klingbeil, C. (2013). Using "Teach-back" to promote a safe transition from hospital to home: An evidence-based approach to improving the discharge process. Journal of Pediatric Nursing, 28(3), 282-291.

Krauss, M. J., Nguyen, S. L., Dunagan, W. C., Birge, S., Costantinou, E., Johnson, S., Fraser, V. J. (2007). Circumstances of patient falls and injuries in 9 hospitals in a Midwestern healthcare system. Infection Control \& Hospital Epidemiology, 28(5), 544-550. 
Kripalani, S., Bengtzen, R., Henderson, L. E., Jacobson, T. A. (2008). Clinical research in low-literacy populations: Using teach-back to assess comprehension of informed consent and privacy information. IRB: Ethics \& Human Research. 30(2), 13-19.

NDNQI, Quality Improvement Solutions from ANA. (2013). Retrieved 10, 2013, from http://www.nursingquality.org/

National Quality Forum (NQF). Safe practices for better healthcare- 2010 update. Retrieved 11/9, 2013, from https://www.qualityforum.org/Publications/2010/04/Safe_Practices_for_Better_Heal thcare_-2010_Update.aspx

National Quality Forum, NQF endorsed standards. (2009). Retrieved 8/30, 2011, from http://www.qualityforum.org

Rook, K. S. (1994). Assessing the health-related dimensions of older adults' social relationships. Annual review of Gerontology, 14, 142-181.

Russell, C. K., Gregory, D. M. (2003). Evaluation of qualitative research studies. Evidence Based Nursing, 6, 36-40, 10.1136/ebn.6.2.36.

Schwartzberg JG, VanGeest JB, Wang CC, eds. Understanding Health Literacy: Implications for Medicine and Public Health. AMA; 2005. 
TJC, the joint commission, speak up initiatives, facts about speak up initiative. (2011). Retrieved 11, 2011, from http://www.jointcommission.org/speakup.aspx

Tzeng, H. M. (2010). Understanding the prevalence of inpatient falls associated with toileting in adult acute care settings. Journal of Nursing Care Quality, 25(1), 22-30.

Tzeng, H. M., \& Yin, C. Y. (2009). Perspectives of recently discharged patients on hospital fall -prevention programs. Journal of Nursing Care Quality, 24(1), 42-49.

U. S. Department of Health and Human Services (2004). Making health communication programs work: Planner's guide. NIH Publication No.04-5145. http://www.cancer.gov/pinkbook

U. S. Department of Health and Human Services (2005). Theory at a glance: A guide for health promotion. $2^{\text {nd }}$ Ed. NIH Publication No. 05-3896. http://www.cancer.gov/cancerinformation/theory-at-a-glance

U. S. Department of Health and Human Services. Healthy people 2010: Understanding and improving health. 2nd ed. Washington, D.C. U. S. government printing offices. November 2000.

U. S. Department of Health and Human Services. Healthy people 2020. Healthy people in healthy communities. Washington, D. C. U. S. government printing office. November 2010. Retrieved from http://www.healthypeople.gov/2020/default.aspx 
VanVoorhis, C. R W., \& Morgan, B. L. (2007). Understanding power and rules of thumb for determining sample sizes. Tutorials in Quantitative Methods for Psychology, 3(2), p. 43-50.

Vogt, W. P. (1999). The Dictionary of Statistics and Methodology ( $2^{\text {nd }}$ ed.). Thousand Oaks, CA: Sage.

VonDras, D. D.,\& Madey, S. F. (2004). The attainment of important health goals throughout adulthood: An integration of the theory of planned behavior and aspects of social support. International Journal of Aging and Human Development, 59(3), 205-234.

Wong, C., A., Recktenwald, A., J., Jones, M., L., Waterman, B., M., Bollini, M., L., \& Dunagan, W., Claiborne. (2011). The cost of serious fall-related injuries at three Midwestern hospitals. Joint Commission Journal on Quality \& Patient Safety, 37(2), 81-87.

Yardley, L., Donovan-Hall, M., Francis, K., \& Todd, C. (2006). Older people's views of advice about falls prevention: A qualitative study. Health Education Research, 21(4), 508. 
Appendix L:

Draft Manuscript 


\title{
Draft Manuscript:
}

\section{Evidence Based Video Falls Education with Teach-Back Shows Potential for Reducing Patient Falls}

\author{
Author \\ Donna S. Hahn, DNP, RN, NEA-BC \\ Vice President Acute Care/Chief Nursing Officer, Administration \\ Sentara RMH Medical Center \\ 2010 Health Campus Drive \\ Harrisonburg, Virginia 22801 \\ United Stated of America \\ dshahn@sentara.com \\ Corresponding Author \\ Kathleen Cox, PhD, RN \\ Professor, University of Virginia School of Nursing \\ Claude Moore Nursing \\ Education Building \\ UVA School of Nursing \\ P.O. Box 800826 \\ Charlottesville VA 22908-0826 \\ United States of America \\ kbc2v@virginia.edu
}

Authors declare no conflict of interests. Video production costs paid by the study organization. 


\section{ABSTRACT}

Prevention of falls in the acute care setting is of importance to nursing leaders from patient quality and financial perspectives. This study sought to reduce falls and falls with injury for older, cognitively intact patients through patient and family education by way of an evidence and theory based video with teach-back. Clinical significance was determined as participants fell less frequently in the group receiving the falls education video with teach-back.

\section{INTRODUCTION AND PURPOSE}

Falls are reported to be the most frequently occurring adverse event for adult patients in hospitals. ${ }^{1}$ Treatments related to hospital acquired conditions, and therefore injuries due to falls in acute care, are no longer reimbursed by the Center for Medicare and Medicaid Services. ${ }^{2}$ The costs to hospitals can be significant as researchers have shown increased lengths of hospital stay after a fall with injury to cause an additional 6.3 to 12 days, and an increased mean cost up to $\$ 13,316$ as a result of serious fall injuries. ${ }^{3,4}$ Falls in the hospital setting are of concern to nursing and are endorsed by the National Quality Forum as a nurse sensitive indicator. ${ }^{5}$ The Magnet Nursing Designation awarded by the American Nurse Credentialing Center has become a coveted credential by many healthcare organizations and standards of Magnet require that hospital personnel monitor fall rates and compare the hospital's performance to national benchmarks; the expectation is that Magnet hospitals sustain results to outperform the mean. ${ }^{6,7}$ 
Evidence based protocols and the literature support multifaceted fall prevention interventions, one of which is falls prevention education to patients and their families. ${ }^{8-11}$ A gap was found in the availability of evidence based falls prevention education for the hospitalized adult patient and no clear identified role for the family; however, there is some evidence that a multimedia delivery of education may improve knowledge and outcomes. ${ }^{9,10}$ The data and literature on falls is predominately focused on the older adult and expertise from health promotion literature encourages a clear target population when designing messages to change health behaviors. ${ }^{12-14}$

The purpose of this study was to develop an evidence based education video on falls prevention for the hospitalized older patient, to include this education to a family member or support person, perform teach-back with the patient, and to compare the difference in fall rates between a comparison group and intervention group. It was anticipated that fall rates in those patients who have viewed the video with family would be lower than patients who have not viewed the video and only received information about fall prevention through a brochure.

\section{THEORETICAL FRAMEWORK}

In developing a program of education for older adults and their family member, the theory of planned behavior (TPB) was aligned with social support theory. ${ }^{12,15-17}$

\section{LITERATURE REVIEW}

\section{Factors related to risk of falling when hospitalized}

Studies suggest multiple risk factors are related to falls in a hospital. Increased age, ${ }^{1,18,19}$ administration of central nervous system and vasoactive medications, ${ }^{1,18}$ and patients 
toileting without assistance ${ }^{19-21}$ are reported as risk factors for falls in the acute care setting. Patients were unaware of how quickly they became unbalanced and weak during hospitalization and verbalized that they were reluctant to bother the busy nursing staff to assist them in toileting. ${ }^{21}$ A lifelong personality trait for risk taking, inattentiveness, and impaired mobility were associated risk for older adult falls in the hospital..$^{22,23}$

Environmental risk factors included a higher percentage of falls occurring in the evening hours, lack of access to ambulatory assistive devices, absence of clear pathways in the hospital room, failing to keep the bed height in the low position, failure to apply brakes on the bed, lack of proper footwear, good lighting, and prompt call bell responses by nursing personnel. ${ }^{18,24,25}$

\section{Insights from patients and caregivers on fall prevention}

Participants criticized beds being left in high position, insufficient fall prevention education, lack of ambulatory devices, cluttered rooms, need for increased monitoring, timely answering of call bells, and lack of physical therapy as problems associated with their recent hospitalization. ${ }^{24}$ Nurses identified cognitive impairment, Alzheimer's, disorientation, patient inability to follow safety instruction, and imbalance/gait problems as the most frequently observed risk factors for patient falls. ${ }^{25}$ A well designed education program with visual cues that engaged the patient and more frequent repetition of fall prevention messages from nurses were recommended improvements. Older adults agreed to the value of falls education; however, they may not heed all of the advice and that some of these older adults believed the messages were for the disabled and not for them. ${ }^{26}$ 


\section{Research on patient and family fall prevention education}

Two Australian studies were found, based on the Health Belief Model to design patient education. These two studies provided some evidence for the use of multimedia patient

education as compared to written education material for cognitively intact older adults. ${ }^{9,10}$ In a three group randomized controlled trial, Haines and colleagues ${ }^{9}$ found participants in the treatment group who received multimedia and written education with a one on one follow-up by a health professional experienced fewer falls. The time spent individually with a patient for one to one follow up ranged from 20 to 36 minutes per patient. The second study used a randomized two group design, with a quasi-experimental control group, and compared the effect of falls prevention education delivered by DVD format or written format to no education. ${ }^{10}$ While both written and DVD methods of education created higher numbers of desired responses to the survey compared to the control group, the DVD method of education delivery was found to produce statistically higher levels of confidence, motivation, and engagement in self-protective strategies using a custom designed survey.

\section{METHODS}

The study utilized a quasi-experimental design with a Phase 1 comparison group and Phase 2 intervention group. Both Phase 1 and Phase 2 groups received usual care for all patients as defined by the study unit protocols on fall prevention which included unit orientation, a falls education brochure, and a fall risk assessment completed on every patient every twelve hours to determine each patient's risk for falling. Patients then received fall prevention interventions based on their fall risk score of high, medium, or 
low. Consent was obtained for all participants including patients in Phase 1 and patients and family members in Phase 2. A daily electronic report of all patients currently on the study unit was developed and included the patient name, room location, age, and current status of consent. Falls and falls with injury were captured for the consented participants and compared between the two groups.

The intervention group was shown an evidence based falls prevention education video, with education messages for patient and family, via the television system in the patient's hospital room. The intervention group also received the fall prevention brochure as part of usual care. The video was activated following consent of the patient and also the family when available. After viewing the video a Registered Nurse used a recommended practice of teach-back with the patient and documented the participants viewing the video and the teach-back. ${ }^{27,28}$ Phase 1 participants received usual care which included a falls education brochure. Unit Registered Nurses were to provide the falls brochure on admission to all patients for review by the patient and document in the patient's electronic medical record that the brochure was given to the patient. The falls brochure was developed based on the same review of the literature as utilized for the treatment video. Phase 1 study period was October through December of 2012 and Phase 2 study period was from February through April of 2013.

The study received approvals from the study organization site's institutional review board and the University of Virginia institutional review board.

\section{Setting and sample}


The study was conducted on a 36 bed nontelemetry medical unit within a 238 bed rural designated sole community hospital located in the Mid-Atlantic region of the United States and was part of an 11 hospital system. The unit was chosen to study fall reduction strategies as it had the most opportunity for reduction at that time with a 5.93 total fall rate and 1.50 falls with injury rate for the year 2011. Participant inclusion criteria were patients admitted or transferred to the study unit, age 60 and over, patients with or without family support, English or Spanish speaking, patients and family who had consented to participate, and absence of diagnosis related to dementia, confusion, Alzheimer's, or other cognitive disability.

\section{Variables}

A fall was defined as any unplanned descent to the floor. A fall with injury was defined as any minor, moderate, or major injury including death. ${ }^{8,13}$ Rates were calculated per 1000 patient days. The organization captures falls through electronic reporting surveillance of nurse documentation and a fall huddle report submitted by nursing which includes the fall details.

\section{Development of an evidence based falls prevention video}

A professional communication and marketing firm was engaged to assist the researcher in development of message concepts. A content outline was developed addressing the three determinants of TPB to influence the patient's behavioral intent and social support theory for messages to guide family to support the patient in behaviors to prevent falls. The social marketing planning process ${ }^{13}$ was used to develop falls prevention messages and communication strategies. Messages were pretested with three patients on the study unit 
who met study inclusion criteria. The patient feedback was consistent with the literature review findings.

The video delivers messages from the content outline by a narrator, two organizational Registered Nurses, and a family member. The family member had previously experienced the loss of a parent due to a serious injury and eventual death related to a fall in another facility.

\section{Research Procedures}

Initial design used trained unit Registered Nurse Case Manager and Charge Nurses collaboratively review the daily report, discuss cognitive status of the patient, and consent patients meeting inclusion criteria. A review of the consent process after the first month of Phase 1 determined that in order to consistently consent patients meeting study criteria dedicated staff would be necessary to systematically attempt to consent patients. Trained Patient Care Technicians were scheduled for several hours per day by the end of Phase 1 of the study in order to dedicate time to the consenting process. Past history of diagnosis related to cognitive dysfunction was added to the daily report, and patients were reviewed with the Charge Nurse prior to attempting consent. Consenting of patients did not occur on the weekends for both Phases of the study due to resource limitations.

During Phase 2, the falls prevention video was initiated by the unit Registered Nurse or Patient Care Technician following patient consent. Poor compliance with documentation and research interventions to consented patients required weekly emails and verbal reminders to Registered Nurses in staff meetings of their roles in the study.

\section{Data analysis}


All statistical tests were performed using SPSS software v. 21. It was determined that target group sample size of 30 would provide $80 \%$ power to detect differences between

groups. ${ }^{29}$ Frequencies and means were calculated for sample characteristics. Phase 1 and Phase 2 groups were compared on demographic characteristics and length of stay variable using appropriate statistical tests such as the t-test and chi-square. The data for length of stay were positively skewed; thus, the Mann Whitney U test was used to compare mean ranks. Generally chi-square test was used to check differences for the delivery of interventions between groups. All statistical significance tests were set at $P<0.05$. Fall and fall with injury rates were calculated per 1000 patient days. Effect size was calculated for strength of association using the Pearson $r$. Fall huddle reports for two patient falls during the study were analyzed for variable trends.

\section{RESULTS}

\section{Findings}

During the study Phase 1 and Phase 2, 1897 patients were admitted or transferred into the study unit setting. Of the 630 patients admitted or transferred to the study unit during Phase 1, $100(16 \%)$ patients consented to participate in the study, 74 (12\%) declined to participated, and $456(72 \%)$ were either not eligible or consent was not attempted. In Phase 2, $92(16 \%)$ of the 565 patients admitted or transferred to the study unit consented to participate in the study, $143(25 \%)$ of the patients declined to participate, and 330 $(58 \%)$ were either not eligible to participate or for which consent was not attempted. Only 17 (19\%) of patients' family/significant others consented to participate in the study 
during Phase 2. Interestingly a higher proportion of patients declined during Phase 2 which may reflect an increased number of patients approached to participate in Phase 2. Demographic and length of stay characteristics between groups are summarized in Table 1. Statistical analysis revealed no missing data. There were no statistically significant differences in characteristics between groups.

There was a statistically significant difference between groups in the proportion of patients receiving any kind of falls educational intervention based on the study phase they were in, $\chi 2(1, \mathrm{~N}=192)=0.20, P<.001$. Interestingly, in Phase 2 , the majority $(82 \%)$ of participants received a falls education intervention (falls brochure or falls brochure and video) while in Phase 1 less than half (42\%) of participants received a falls education intervention (brochure). The effect size for this analysis $(\mathrm{Phi}=.41)$ was found to exceed Cohen's ${ }^{30}$ convention for a medium effect $(r=0.30)$. A similar number of consented patients in Phase 2 had documentation in their medical record that they received the falls prevention brochure $(n=44,48 \%)$. A small portion of participants in Phase $2(n=7$, $8 \%$ ) had documentation of viewing the video with their family/significant other even though this represents less than half the number of family members who consented to participate $(\mathrm{n}=17)$.

Two falls occurred without injury during Phase 1 and no falls or falls with injury occurred during Phase 2. Phase 1 fall rate was 6.01 (2 falls/333 patient days $x 1000$ patient days). Phase 2 fall rate was 0.0 (0 falls/347 patient days x 1000 patient days). The effect size for this analysis $(\mathrm{Phi}=.10)$ was found to just meet Cohen's ${ }^{30}$ convention for a small effect $(r=0.10)$. The low number of falls during both Phases did not allow 
for a statistical difference between the Phase 1 and Phase 2 groups nor the ability to run any statistical analysis for differences between rates. No falls with injury occurred in either Phase 1 or Phase 2.

Comparison of Post-Fall Huddle Forms between the patient falls revealed falls occurred within 2 and 5 hours following administration of opiates for pain and occurred when the male patients attempted to toilet without calling for the nurse. Nursing had performed rounds on each patient within an hour of the patient's fall. The risk assessment tool scored one patient as a moderate risk and the other as a high risk, with one patient having a history of a fall at home within the past six months. Only one of the fall patients had documentation of receiving the fall prevention brochure. Neither fall resulted in an injury.

\section{Discussion}

The purpose of the study was to reduce falls and falls with injury in the older hospitalized adult. Viewing of a falls prevention education video by the patient and family support member was intended to increase the patient's knowledge of fall risk, influence their behavioral intent to follow fall prevention strategies, and improve understanding by the family support member on their role in supporting the patient in fall prevention behaviors. No statistical evidence was found to support the study hypothesis due to the small number of patients with family support consenting and viewing the evidence based falls prevention video $(n=7)$. The small number of falls occurring during either Phase of the study prevented planned statistical analysis for comparison of the two study Phase groups. 
While the study did not reinforce social support theory as a component for the theoretical model, the study may indicate the benefit for use of evidence based messages with patients based on the TPB when measuring and comparing fall rates from a clinically significant improvement aspect. The clinical significance derives from findings that the majority of patients $(82 \%)$ in Phase 2 received the brochure and/or video fall prevention education with messages based on the TPB and fell less frequently ( 0 per 1000 patient days) than patients in the Phase 1 comparison group. Phase 1 comparison group participants received a falls education brochure less than half the time (42\%) and fell more frequently (6.01 per 1000 patient days).

Interestingly, implementing the falls education video in Phase 2 increased the number of patients overall who received some type of education; $82 \%$ received either the brochure alone or the brochure and the video, while in Phase 1 only $42 \%$ received the brochure. The fidelity of patients receiving the brochure during Phase 2 was not so different (48\%) than during Phase $1(42 \%)$. Therefore, there may be clinical significance for patients in Phase 2 receiving falls prevention education by video (70\%), and teach-back performed the majority of the time (94\%), with falling less frequently than patients receiving usual care including the brochure. Analysis revealed a statistically significant difference $(P<$ .001) between these groups related to patients receiving falls prevention education and the effect size for this difference exceeded Cohen's ${ }^{30}$ convention for a medium effect. Effect size is said to emphasize the size of the difference and estimates the magnitude of effect between groups without regard to sample size. ${ }^{31,32}$ 
Standards of the American Nurses Credentialing Center's Magnet Recognition Program® set the expectation for hospitals to outperform nationally benchmarked mean comparisons fall rates. ${ }^{7}$ The National Database of Nurse Sensitive Indicators (NDNQI) ${ }^{33}$ is one source of national benchmark data for nurse sensitive indicators and used by many hospitals. Of clinical significance to this study, the NDNQI mean fall rate for the 746 like units for comparison to the study unit in the fourth quarter 2012 (Phase 1) was 3.81 (SD 2.13) as compared to the Phase 1 participant fall rate of 6.01 (approached the $90^{\text {th }}$ percentile performance for this quarter benchmark). The NDNQI mean fall rate for the first quarter 2013 (Phase 2) for 768 like units for comparison was 3.60 (SD 2.06) as compared to the study unit's participant rate of 0 (below the $10^{\text {th }}$ percentile in comparison group). While there is no statistical difference in fall rates between the groups, these national benchmark comparisons are important in light of the statistical differences and medium effect size between the groups in the percentage of patients who received any type of fall prevention education.

Although the small numbers of falls in either group hindered analysis of statistical comparison for falls between groups, the effect size met Cohen's ${ }^{30}$ convention of 0.10 for a small size effect. Durlak ${ }^{31, p .924}$ discussed the need for researchers to evaluate the practical or clinical significance in the context of "the extent to which there has been a meaningful change in participants' lives”. Researchers are instructed to interpret the effect size in relation to how difficult an outcome is to obtain when evaluating clinical significance. ${ }^{31}$ An effect size of 0.10 with an outcome that is difficult to obtain may be of greater clinical significance than an effect size of 0.50 when the outcome is relatively 
easy to obtain or less critical to the health of participants. ${ }^{31}$ Falls in the acute care setting have been a difficult problem to eradicate and at times devastating to the life of the older adult. Therefore this small effect size finding may be of clinical significance in the search for fall prevention interventions.

The statistical differences in the percentage of patients who received any type of falls prevention education between the Phase 1 and Phase 2 groups may support previous study findings. Hill and colleagures ${ }^{10}$ compared DVD education, workbook education and a control group receiving no education. Participant's improvements in knowledge of falls and prevention improved to a greater extent using the DVD method, but both treatment groups were statistically significantly for improvement as compared to the control group. Phase 2 results of this current study indicate a high percentage of patients received the video education $(70 \%)$ as a targeted intervention and there was a statistically significant difference in the number of patients receiving any falls education between Phase $1(42 \%)$ and Phase $2(82 \%)$. Thus the lower fall rates in Phase 2 of this current study may support Hill and colleagues' previous work for effectiveness of theory based falls education.

The current study findings for lower fall rates for older adults receiving video falls prevention education followed by teach-back may also be consistent with previous research by Haines and colleagues. ${ }^{9}$ This previous study, a randomized 3-group trial, compared a video and written materials falls prevention education intervention with follow up by a health counselor, a video and written materials only intervention, and no specific falls education control group. Fall rates for this previous study were much lower 
in the cognitively intact group receiving video and written materials with a health counselor follow up (4.01 per 1000 patient days) than the video and materials only group (8.18 per 1000 patient days). Both intervention groups had lower fall rates than did the control group ( 8.72 per 1000 patient days). The health counselor follow up in this pervious study was time intensive taking between 20 and 36 minutes per patient and study design allowed a week for this counseling to occur. Similarly, in a 6 week student performance improvement project on a neuroscience unit, patient and family education

resulted in no falls; however, the teaching time ranged from 5 to 20 minutes. ${ }^{34}$ The teachback method of this current study served as a less resource intensive intervention and within the length of stays of U.S. hospitals.

The information from the fall huddle reports for the two patients that fell during Phase 1 did not provide any further evidence for refinement to messages contained in the falls prevention video.

\section{Limitations}

It is important to note the limitations of this study. First, the nonrandomized study was conducted in one unit in one acute care facility. The study needs to be conducted in different types of units in multiple health care organizations. Second, the sample size was too small to conduct the planned statistical analysis. The small sample size was likely related to the failure of nursing personnel to consistently perform and/or document interventions, and the difficulty in procuring consent from both patients and families. Third, the relatively short duration of the study was a limitation. Finally, no test of cognitive function was performed prior to consenting patients and therefore it is possible 
that participants may have been included in the study that had some confusion or cognitive impairment

\section{Implications for future research}

In addition to replicating the study in different types of units in multiple health care organizations over a longer period of time, there are other implications for research. Future research might also be conducted to determine if allowing family members of cognitively impaired patients to view the video with teach-back and measure the impact of falls for this challenging population of patients. Future research should be conducted not only to determine the impact of evidence and theory based videos on patient falls, but also to determine which combinations of interventions are most effective in preventing falls.

\section{Implications for nursing administrative practice}

Although the hypothesis was not supported, there were fewer falls in the Phase 2 intervention group than in Phase 1 comparison group, and previous studies using multimedia education was supported, which is of clinical significance to nursing practice. Thus, nursing leaders should indeed continue to implement and evaluate falls prevention protocols that include video based education and teach-back. As health care reform advances, reimbursement will be reduced and transition from volume based payment to patient clinical outcome based payment will challenge organizations to reduce costs while improving their benchmark comparison rankings. It is imperative that as nurse leaders effective and efficient ways are developed to assure patients are educated and better motivated to follow behaviors that promote health. Theory and evidence based 
education videos with teach-back may be an efficient technological tool to engage patients in fall prevention. Using evidence based messages to develop videos and other educational materials could provide a new standard of practice for the prevention of falls and other adverse outcomes as well as provide patients and families some control over those outcomes. 


\section{REFERENCES}

1. Currie L. Fall and injury prevention. In: Hughes RG, ed. Patient safety and quality: An evidence-based handbook for nurses. AHRQ Publication No. 08-0043. Rockville, MD: Agency for Healthcare Research and Quality, US Department of Health and Human Services; 2008:195-250. http://www.ncbi.nlm.nih.gov/books/NBK2653/.

2. CMS, Center for Medicare and Medicaid Services: Hospital acquired conditions. https://www.cms.gov/hospitalacqcond/06_hospital-acquired_conditions.asp. Updated 2011. Accessed September 11, 2011.

3. Bates DW, Pruess K, Souney P, Platt R. Serious falls in hospitalized patients: Correlates and resource utilization. Am J Med. 1995;99(2):137-143.

4. Wong CA., Recktenwald AJ, Jones ML, et al. The cost of serious fall-related injuries at three midwestern hospitals. Joint Comm J Qual Patient Saf. 2011;37(2):81-87.

5. National Quality Forum, NQF Endorsed Standards. http://www.qualityforum.org. Updated 2009. Accessed August 30, 2011.

6. ANCC, American Nurses Credentialing Center, Magnet Program Overview. http://www.nursecredentialing.org/Magnet/ProgramOverview.aspx. Updated 2012. Accessed March, 2012.

7. American Nurse Credentialing Center. Recognizing Nursing Excellence Application Manual, Silver Springs, MD: Magnet Recognition Program; 2008. 
8. Degelau J, Belz M, Bungum L, et al. Prevention of falls (acute care). Updated April 2012. https://www.icsi.org/_asset/dcn15z/Falls.pdf. Accessed October 19, 2013

9. Haines TP, Hill AM, Hill KD, et al. Patient education to prevent falls among older hospital inpatients: A randomized controlled trial. Arch Intern Med. 2011;171(6):516524.

10. Hill A, McPhail S, Hoffmann T, et al. A randomized trial comparing digital video disc with written delivery of falls prevention education for older patients in hospital. $J$ Am Geriatr Soc. 2009;57(8):1458-1463.

11. Dykes PC, Carroll DL, Hurley AC, Benoit A, Middleton B. Why do patients in acute care hospitals fall? Can falls be prevented?. J Nurs Adm. 2009;39(6):299-304.

12. Edberg, M. Individual health behavior theories. In Reigelman, R, ed. Essentials of health behavior: social and behavioral theory in public health. Sudbury, MA:Jones \& Bartlett Learning; 2007:35-49.

13. US Department of Health and Human Services. Making health communication programs work: planners guide. NIH Publication No.04-5145. 2004. Accessed June, 2012. http://www.cancer.gov/pinkbook.

14. U. S. Department of Health and Human Services. Theory at a glance: A guide for health promotion. $2^{\text {nd }}$ Ed. NIH Publication No. 05-3896. 2005. Accessed June, 2012. http://www.cancer.gov/cancertopics/cancerlibrary/theory.pdf 
15. Ajzen, I. The theory of planned behavior. Organizational Behavior and Human Decision Processes. 1991:50; 179-211.

16. Rook, KS. Assessing the health=related dimensions of older adults'social relationships. Annual reviewof Gerentology. 1994;14: 142-181

17. VonDras, DD, Madey, SF. The attainment of important health goals throughout adulthood: an integration of the theory of planned behavior and aspects of social support. Int J Aging Hum Dev. 2004;59(3): 205-234.

18. Hitcho, EB, Krauss, MJ, Birge, S, et al. Characteristics and circumstances of falls in a hospital setting. J Gen Intern Med. 2004;19(7): 732-739.

19. Krauss, MJ, Nguyen, SL, Dunagan, WC, et al. Circumstances of patient falls and injuries in 9 hospitals in a midwestern healthcare system. Infection Control and Hospital Epidemiology. 2007;28(5); 544-550.

20. Tzeng, HM. Understanding the prevalence of inpatient falls associated with toileting in adult acute care settings. J Nurs Care Qual. 2010;25(1): 22-30.

21. Carroll, DL, Dykes, PC, Hurley, AC. Patients' perspectives of falling while in an acute care hospital and suggestions for prevention. Appl Nurs Res. 2010;23: 238-241.

22. Kloseck, M; Crilly, RG; Gibson, M. Can [personality theory help us understand risk of falls? J Rehabil Res Dev. 2008;45(8): 1125-1134. 
23. Ferrari M, Harrison B, Campbell C, Maddens M, Whall A. Contributing factors associated with impulsivity-related falls in hospitalized, older adults. J Nurs Care Qual. 2010;25(4): 320-326. http://journals.lww.com/jncqjournal/pages/default.aspx. Accessed November 15, 2013.

24. Tzeng, HM, Yin, CY. Perspectives of recently discharged patients on hospital fallprevention programs. J Nurs Care Qual. 2009;24(1): 42-49.

25. Tzeng HM, Yin CY. Frequently observed risk factors for fall-related injuries and effective preventive interventions: A multihospital survey. J Nurs Care Qual. 2013;28(2): 130-138. http://journals.lww.com/jncqjournal/pages/default.aspx. Accessed November 15, 2013.

26. Yardley L, Donovan-Hall M, Francis K, Todd C. Older people's views of advice about falls prevention: A qualitative study. Health Educ Res. 2006;21(4): 508-517.

27. Institute for Healthcare Improvement (IHI). Always use teachback. http://www.ihi.org/knowledge/Pages/Tools/AlwaysUseTeachBack!.aspx. Updated 2013. Accessed November 10, 2013.

28. National Quality Forum (NQF). Safe practices for better healthcare- 2010 update. https://www.qualityforum.org/Publications/2010/04/Safe_Practices_for_Better_Healthcar e_-_2010_Update.aspx. Accessed November 9, 2013. 
29. VanVoorhis, C. R W., \& Morgan, B. L. Understanding power and rules of thumb for determining sample sizes. Tutorials in Quantitative Methods for Psychology, 2007;3(2): 43-50.

30. Cohen, J. A power primer. Psychological Bulletin. 1992;112(1): 155-159.

31. Durlak, J. How to select, calculate, and interpret effect sizes. Journal of Pediatric Psychology, 2009;34(9): 917-928.

32. Ferguson, C. J. (2009). An effect size primer: A guide for clinicians and researchers. Professional Psychology: Research and Practice. 2009;40(5): 532-538.

33. NDNQI, Quality Improvement Solutions from ANA. http://www.nursingquality.org/. Updated 2013. Accessed October 19, 2013.

34. Ryu Y, Roche J, Brunton M. Patient and family education for fall prevention: Involving patients and families in a fall prevention program on a neuroscience unit. Journal of nursing care quality. 2009;24(3): 243-249. http://journals.lww.com/jncqjournal/pages/default.aspx. Accessed November 15, 2013. 
Table 1. Group Demographics and Length of Stay Characteristics

\begin{tabular}{|c|c|c|c|}
\hline & $\begin{array}{l}\text { Group 1 } \\
\text { Phase 1 } \\
\text { Falls Brochure }\end{array}$ & $\begin{array}{c}\text { Group 2 } \\
\text { Phase 2 } \\
\text { Falls Brochure, } \\
\text { Video, } \\
\text { and Teach-Back }\end{array}$ & \\
\hline Variable & $(n=100)$ & $(n=92)$ & $P$ \\
\hline Gender, $n(\%)$ & & & $>0.05$ \\
\hline Male & $36(36)$ & $36(39.1)$ & \\
\hline Female & $64(64)$ & $56(60.9)$ & \\
\hline $\begin{array}{l}\text { Primary Language, } \\
n(\%)\end{array}$ & & & $>0.05$ \\
\hline English & $100(100)$ & $91(98.9)$ & \\
\hline Spanish & $0(0)$ & $1(1.1)$ & \\
\hline Race, $n(\%)$ & & & $>0.05$ \\
\hline African & $3(3)$ & $3(3.3)$ & \\
\hline American & $96(96)$ & $84(91.3)$ & \\
\hline Caucasian & $1(1)$ & $1(1.1)$ & \\
\hline Hispanic & $0(0)$ & $4(4.3)$ & \\
\hline \multicolumn{4}{|l|}{ Other } \\
\hline Age, Mean (SD) & 74.05 (7.933) & 74.16 (8.499) & $>0.05$ \\
\hline LOS, Mean (SD) & $3.33(3.77)$ & 3.77 (3.762) & $>0.05$ \\
\hline
\end{tabular}

